\title{
Preliminary Report on the Survey of Hajjiabad- Varamin, a Site of the Konar Sandal Settlement Network (Jiroft, Kerman, Iran)
}

Nasir Eskandari, François Desset, Mojgan Shafiee, Meysam Shahsavari, Salman Anjamrouz, Irene Caldana, Ali Daneshi, Ali Shahdadi \& Massimo Vidale

To cite this article: Nasir Eskandari, François Desset, Mojgan Shafiee, Meysam Shahsavari, Salman Anjamrouz, Irene Caldana, Ali Daneshi, Ali Shahdadi \& Massimo Vidale (2021): Preliminary Report on the Survey of Hajjiabad-Varamin, a Site of the Konar Sandal Settlement Network (Jiroft, Kerman, Iran), Iran, DOI: 10.1080/05786967.2021.1936595

To link to this article: https://doi.org/10.1080/05786967.2021.1936595

册Published online: 14 Jun 2021.

Submit your article to this journal $₫$

Q View related articles $\longleftarrow$

View Crossmark data $\nearrow$ 


\title{
Preliminary Report on the Survey of Hajjiabad-Varamin, a Site of the Konar Sandal Settlement Network (Jiroft, Kerman, Iran)
}

\author{
Nasir Eskandari $\mathbb{P}^{a, b, c}$, François Desset ${ }^{d}$, Mojgan Shafiee ${ }^{d}$, Meysam Shahsavari ${ }^{c}$, Salman Anjamrouz ${ }^{c}$, \\ Irene Caldana ${ }^{\mathrm{e}, \mathrm{f}}$, Ali Daneshi ${ }^{\mathrm{c}}$, Ali Shahdadi ${ }^{\mathrm{c}}$ and Massimo Vidale ${ }^{\mathrm{e}, \mathrm{f}}$ \\ ${ }^{\mathrm{a} D e p a r t m e n t ~ o f ~ A r c h a e o l o g y, ~ U n i v e r s i t y ~ o f ~ T e h r a n, ~ T e h r a n, ~ I r a n ; ~}{ }^{\mathrm{b}}$ Center for International Scientific Studies and Collaboration (CISSC), Ministry \\ of Science Research and Technology, Tehran, Iran; ${ }^{\mathrm{C}}$ Department of Archaeology, University of Jiroft, Jiroft, Iran; ${ }^{\mathrm{d}}$ CNRS Team Archéorient, UMR

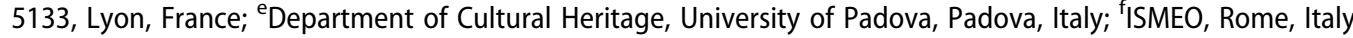

\section{ABSTRACT}

The purpose of this article is to introduce the large prehistoric site of Hajjiabad-Varamin, its changes in time and the first discoveries made there, in the specific literature on the early Bronze Age of the south-eastern Iranian Plateau. The first part of the article describes the site, its present damaged conditions, the periodisation we adopted and the complex topographic shifts and changes of functions through time. The second part focuses on the settlement of the 3rd millennium BC and discusses a major craft activity area found east of the main elevation of the site, in which were manufactured vessels in various stones (white alabaster, grey limestones with white fossil inclusions, and probably chlorite). Collections include large drill-heads in volcanic rocks used on the interior of the stone pots, and standardised beads of a green and red-banded calcite broken while being drilled. While the stone vessels find abundant comparisons and were certainly in demand for long-distance trade, the beads type is not known in other contexts and were presumably made for a local demand. We also present the unusual find of a hoard of copper objects which helps framing the 3rd millennium BC centre in terms of cultural links and chronology.

\section{KEYWORDS}

Hajjiabad-Varamin; Konar Sandal sites network; Hali Rud civilisation; surface survey; craft activity areas

\section{Introduction}

After the first information provided by a famous survey of A. Stein, ${ }^{1}$ the construction of a reliable archaeological framework for the development of the Halil Rud or Jiroft Bronze Age civilisation is still an enduring effort. The attention first drawn by books illustrating the types and the impressive iconography of hundreds of objects recovered from grave looters, ${ }^{2}$ soon bounced in popular archaeology magazines. ${ }^{3}$ Much wanted scientific reports dealing with the ancient settlements and ecological conditions of the valley, and the first results of the stratigraphic digs by Y. Madjidzadeh at Konar Sandal South, appeared in the following years. ${ }^{4}$

Of course, the academic community was both stunned and dubious, while confronting the unexpected evidence of new, large early urban sites in the Kerman region, the amount and the amazing aesthetic and technical standards of the recovered artefacts, not to mention the discovery, in regular excavations, of terracotta tablets with an unknown "writing" system of the 3rd millennium BC. A crucial issue was how such a sophisticated civilisation could have suddenly bloomed out of what appeared an unimpressive (albeit poorly known) local prehistoric background. Stated in these terms, the question had important implications for the general understanding of the rise of Bronze Age urbanism across the entire Iranian Plateau.

For this reason, in the past decade, scholars rather focused on the prehistoric foundations of the region, actively refitting a long sequence (mainly based on pottery assemblages) that now stretches from middle Neolithic to early historic times. In the emerging picture, the late Chalcolithic (4th millennium BC) may be seen as a

CONTACT Nasir Eskandari nasir.eskandari@ut.ac.ir

${ }^{1}$ Stein, Archaeological Reconnaissances in North-Western India and South-Eastern Iran.

${ }^{2}$ Madjidzadeh, Jiroft: The Earliest Oriental Civilization; Piran and Hesari, Cultural Around Halil Roud and Jiroft; Piran and Madjidzadeh, Objects from the Jiroft Treasury; Perrot and Madjidzadeh, "L'Iconographie des Vases et Objects en Chlorite de Jiroft"; and "A travers I'ornementation des vases et objets en chlorite de Jiroft."

${ }^{3}$ Perrot and Madjidzadeh, "Jiroft, Fabuleuse Découverte en Iran."

"Fouache et al., "Dynamiques géomorphologique dans la vallée de I'Halil Roud"; Fouache, "Jiroft II. Human Geography and Environment"; Madjidzadeh and Pittman, "Excavations at Konar Sandal."

(c) 2021 British Institute of Persian Studies 
crucial phase of socio-political integration, ${ }^{5}$ while the local presence of an Uruk-related settlement of the second half of the 4 th millennium $\mathrm{BC}$, at present, seems an intrusion rather than a generalised chronological horizon. ${ }^{6} \mathrm{New}$ results on the transition between the 4th and the 3 rd millennium BC, and rescue work at the destroyed graveyard of Mahtoutabad were also preliminary reported in recent publications, or are in press. ${ }^{7}$ While this growing amount of information is currently invested by the Iranian Centre for Archaeological Research and the University of Tübingen in a major project of surface regional survey of the southern part of the Halil Rud valley, ${ }^{8}$ we report here the results of the first intensive and systematic intra-site reconnaissance of Hajjiabad-Varamin: a large, rather damaged site near Konar Sandal South, having a long settlement history.

Surface analysis notoriously obeys to heavy constraints. From many viewpoints, contexts highly relevant for answering crucial questions remain open and not controlled. At the end of the paper, Sections 5 and 6 , respectively dealing with a stone-working area and a recovered copper hoard (3rd millennium BC), risk to appear disconnected from the rest. However, these two finds represent closed, homogeneous contexts of study, and this, we believe - together with their archeological relevance - justifies the space here given to their discussion.

\section{Overview of the Site}

Hajjiabad-Varamin (late 5th-second half of the 3rd millennia $\mathrm{BC},{ }^{9}$ later inhabited in the early historic and Islamic periods) is only a part of an enormous archaeological settlement network pivoted on the hub of a large settlement extending from Konar Sandal South to Konar Sandal North. This network extends for not less than 12 (north to south) $\times 7 \mathrm{~km}$ (east to west) and, so far, has been explored only in a partial way (Figures 1 and 2). About $1.5 \mathrm{~km}$ to the north of
Hajjiabad-Varamin lays the separate site of MarjanVaramin, also extensively occupied during the 4th and 3rd millennia BC. As the gap appears void of cultural materials, we have to consider the two archaeological locations as individual sites.

To delimitate with precision the extension of this network is far from easy. At distances of $4-6 \mathrm{~km}$ to the south/south west, the ICAR-Tübingen South of Jiroft Archaeological Survey (hereafter SOJAS) located several early Bronze Age mounds. ${ }^{10}$ The wide, extensively looted cemetery area of Rig Anbar lies approximately $4 \mathrm{~km}$ to the south-east of Hajjiabad-Varamin. ${ }^{11}$ About $6 \mathrm{~km}$ to the north-east, as stated above, the major early urban site of Konar Sandal South, was occupied through good part of the 3rd millennium BC, and was certainly linked to the multi-stratified site of Mahtoutabad (800 m north-east of the Konar Sandal South citadel). Settled since about $4000 \mathrm{BC}$, around the mid-3rd millennium $\mathrm{BC}$ this area hosted an important graveyard for the community living in Konar Sandal South.

Hajjiabad-Varamin (map in Figure 3, general view in Figure 4) is cut in two by the present Jiroft-Boluk paved road. It appears as a wide, rather disturbed extension of low elevations cut by old and recent shallow erosive gullies. The surface is strewn with pebbles, lithic industry, pottery and overfired ceramics. Sparsely covered with shrubs and patches of desert grass, it is frequently used as grazing ground by flocks of sheep and goats. It should be stressed that the surface record of ceramics, at present, is not particularly reliable. Besides the damages of a generalised, destructive erosion, the map of Figure 3 shows how much of the surface of the southern part of the Hajjiabad-Varamin site was recently levelled flat. At north, many graves of the late 4th-early 3rd millennium BC were opened and destroyed by robbers, the pots broken in large shards scattered nearby, eventually mixing with those of earlier and later phases of occupations. Moreover, the SOJAS project, before our survey, had carried out at Hajjiabad-Varamin an intensive surface collection of

\footnotetext{
${ }^{5}$ For the Neolithic foundations, Soleimani, "First Season of Excavation in Tape Gavkoshi," and "Tappeh Gāvkoshi Esfandagheh Jiroft"; Soleimani and FazeliNashli, "The Reevaluation of Kerman Neolithic Chronology." For the Chalcolithic, see the recent chronological re-assessment of Shafiee et al., "Gahnegari nesbi va motlaq Tappeh Vakilabad Ourzouyeh"; Vidale and Desset, "Mahtoutabad I (Konar Sandal South, Jiroft)"; Solaimani et al., "Khaje Askar"; Mutin, "Cultural Dynamics in Southern Middle-Asia" and "Ceramic Traditions and Interactions"; Mutin et al., "New Discoveries in the Bampur Valley" and "Regional and Long-Distance Exchanges of an Emblematic 'Prestige' Ceramic"; Eskandari, "Excavations at the Prehistoric Sites of Tepe Dehno and Tepe East Dehno, Shahdad" and "A Reappraisal of the Chronology of the Chalcolithic Period in SE Iran." We fully agree with Pfälzner and Soleimani, "The ICAR - University of Tübingen South-of-Jiroft Archaeological Survey," 136, that "... The Late Chalcolithic, especially the 'Aliabad period', can be regarded as the formative phase of the urban culture of the Bronze Age in the Jiroft region."

${ }^{6}$ Desset et al., "Mahtoutabad III (Province of Kerman, Iran)."

"Eskandari et al., "Excavations at the Bronze Age Pastoral Site of Hanzaf"; Eskandari et al., "A Late 4th to Early 3rd Millennium BC Grave in Hajjiabad-Varamin" and "The Formation of the Early Bronze Age Jiroft Culture." For the graves of Mahtoutabad, Vidale, "Searching for Mythological Themes"; Desset et al., "A Grave of the Halil Rud Valley"; and Vidale, "Jiroft La civiltà che non c'era."

${ }^{8}$ Pfälzner and Soleimani, "The ICAR - University of Tübingen South-of-Jiroft Archaeological Survey." This reports may be consulted also for additional references to previous research.

${ }^{9}$ Late Chalcolithic 2 in Ibid.

${ }^{10}$ Ibid., 130-1.

${ }^{11}$ Ibid., fig. 24; see our Figure 2.
} 


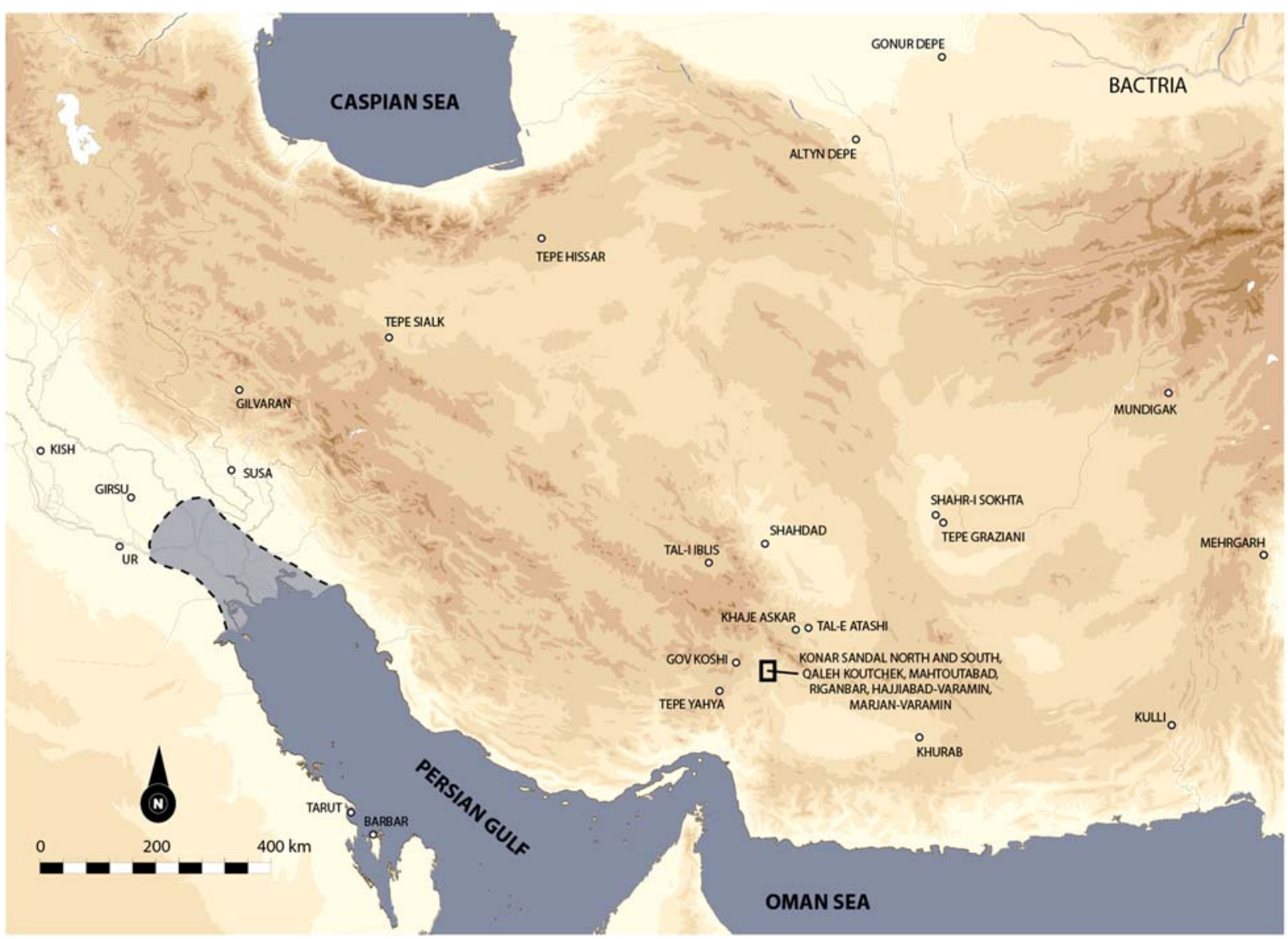

Figure 1. General map of the archaeological sites mentioned in the text.

potsherds. ${ }^{12}$ We cannot evaluate the impact of this collection on the original surface record, and can only wait for the publication of the collected materials.

The north-eastern extensions of the site host wide and fertile fields. To the south-east, east of the paved road, the margin of the site is covered by palm groves, private dwellings and shops of the present Gaz Saleh village. In the north-western part, the main prehistoric mound (hereafter Main Mound), locally damaged by several illegal trenches, rises to a maximum height of 6-7 $\mathrm{m}$ above the present surface. From here, the surface gradually slopes towards east and south-east. The main mound area (about 20 ha, c. $500 \mathrm{~m}$ north to south $\times$ $400 \mathrm{~m}$ east to west) is physically delimited by palms and patches of other agricultural lots, now watered with electric pumps.

The eastern slopes of the Main Mound are heavily disturbed by a dense cluster of illegal pits, whose excavation dirt it is studded with large pottery sherds stylistically datable to the mid-second half of the $3 \mathrm{rd}$ millennium $\mathrm{BC}$, to a great extent coming from destroyed graves. In fact, local villagers reported that looting in this place brought to light carved chlorite artefacts. This is confirmed by the recovery in the excavation dirt of a fragment of a bird-like gaming board in chlorite. This cemetery, now totally or partially destroyed, seems to have originally extended at least for 5-6 ha (see below).

Probably this burial ground re-occupied a minor part of a much wider necropolis of the late 4th-early 3 rd millennium BC, which (judging from disturbed surface contexts, and with unknown densities) might have occupied at least 25/30 ha of surface. In the area east of the paved street the floors of the large catacomb chambers of this period are found about $0.4-0.7 \mathrm{~m}$ or little more from the present disturbed surface. Thus, we can estimate that in the central-eastern stretches of the site, in the course of time, weathering and possibly prolonged agricultural earthworks had removed not less than 1.5-2 $\mathrm{m}$ or more of sediments, thus creating a surface record in which materials of different periods were superimposed and mixed together. The total

\footnotetext{
${ }^{12}$ Ibid., 116, footnotes 71-3.
} 




Figure 2. Google Earth aerial picture of the archaeological area south of Jiroft, showing the location of some of the main archaeological areas nearby the Konar Sandal sites network mentioned in the text.

destruction of some Islamic graves also confirms the deep impact of local erosion.

\section{Fieldwork and Stratigraphy}

Figure 3 shows the location of the 13 small test trenches dug around the periphery for delimiting the site (in Arabic numbers) and that of the 10 Trenches so far excavated on inner stratified contexts (numbered I to $\mathrm{X}){ }^{13}$ Table 1 reports in summary the locations and

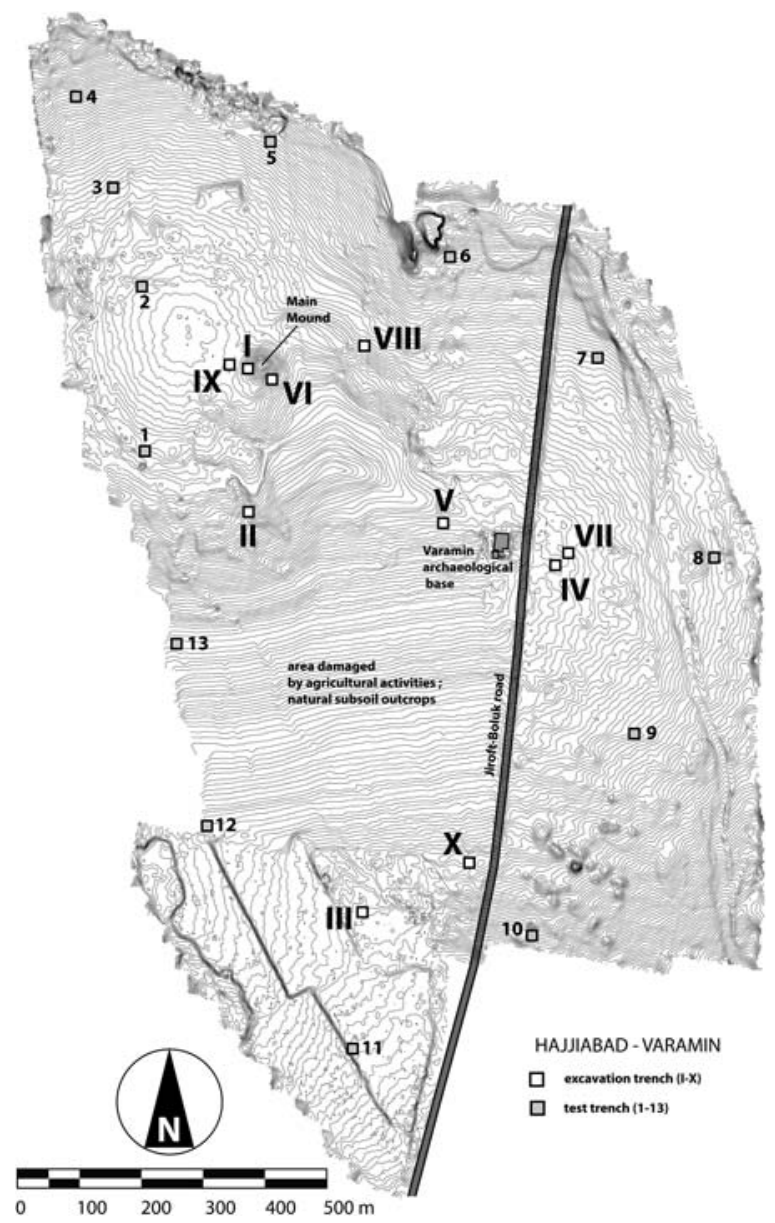

Figure 3. Hajjiabad-Varamin. General topography of the site, with the location of the various trenches (1-13 and I-X) excavated by the project between 2017 and 2019 .

the unearthed contexts of Trenches I to X within the site. $^{14}$

Trench I was dug on the top of the Main Mound to a depth of $3.2 \mathrm{~m}$, without reaching the virgin soil. The details and absolute dates of the various superimposed occupation in the Main Mound revealed by Trench I are the subject of a separate report, describing four superimposed architectural levels and the associated pottery, well dated by the means of eight $14 \mathrm{C}$ dates. ${ }^{15}$ On top of the mound were found large intersecting walls of a major building erected in the first half of the 3rd millennium BC. Below, two other construction levels with less substantial walls (dated around 35002900 BC) contained small and not very abundant sherds, painted with a limited repertory of simple geometric patterns, and comparable to a minor component

\footnotetext{
${ }^{13}$ The preliminary excavations at Hajjiabad-Varamin were made in the frame of a wide collaboration which has variously involved the Universities of Tehran and Jiroft, ICCHTO; and on the Italian side the University of Padua and ISMEO. In February 2017, N. Eskandari, then at the University of Jiroft, dug two Trenches on the Main Mound with the collaboration of Tübingen University (Germany).

${ }^{14}$ Tepe Varamin was actually found and registered as a national site in 1380/2002, with the number 4598 .

${ }^{15}$ See Eskandari et al., "The Formation of the Early Bronze Age Jiroft Culture."
} 




Figure 4. Hajjiabad-Varamin. General view of the site from west, with the Main Mound in background.

of local black-on-buff ceramics accompanying the Mahtoutabad III or Uruk-related ceramic assemblages found at Mahtoutabad (late 4th millennium BC). ${ }^{16}$ The excavation of the nearby Grave I brought to light closely comparable vessels, supporting the identification of a local cultural phenomenon labelled Varamin period. ${ }^{17}$

The lowermost layers of Trench I belong to a Late Aliabad horizon, now rather firmly dated between 3700 and 3400-3300 BC after the correlation of different excavations and surveys in different regions of southeastern Iran: at Tall-i Iblis Period IV, in the Daulatabad Plain, in Tepe Dehno II at Shahdad, and reportedly in the Bampur valley. ${ }^{18}$ In February 2019, the nearby Trench IX was dug for sampling purposes. We reached the virgin soil below the late Aliabad horizon at a depth of about $4 \mathrm{~m}$ from top; above a natural bank of silt we observed a natural paleo-soil, still of unknown age, which suggests previous moister climatic conditions in early/middle Holocene times. Soil samples are currently under study by C. Nicosia.

In 2019, in order to determine the extent of the site, 13 other small test trenches $(1.5 \times 1.5 \mathrm{~m}$ in size $)$ were opened all around the outer border of the site (Figure 3; Trenches 1-13). Variable in depth (but usually less than $1 \mathrm{~m}$ ), these operations generally unearthed erosive secondary lenses on top, variously altered by recent soil formation or recent agricultural impact, and then followed by natural subsoil. We thus enclosed the site (including all the occupations of various periods) within a total area of about 80 ha.
Table 1. Summary of the Trenches excavated at HajjiabadVaramin between 2017 and 2029, with main results.

\begin{tabular}{|c|c|c|}
\hline Trench & Location & Description of unearthed contexts \\
\hline I & Main Mound, top & $\begin{array}{l}3,20 \text { m deep stratigraphic section; on } \\
\text { top, walls of a massive building with } \\
\text { Varamin period pottery (see below); } \\
\text { below, layers with Aliabad pottery }\end{array}$ \\
\hline II & $\begin{array}{l}\text { Main Mound, south } \\
\text { slopes }\end{array}$ & Catacomb Grave 1 \\
\hline III & $\begin{array}{l}\text { Southern extension of } \\
\text { the site }\end{array}$ & $\begin{array}{l}\text { Gaz Saleh layers below eroded surfaces } \\
\text { with Mahtoutabad I/Early Aliabad } \\
\text { ceramics }\end{array}$ \\
\hline IV & $\begin{array}{l}\text { Varamin period } \\
\text { graveyard, eastern } \\
\text { side }\end{array}$ & $\begin{array}{l}\text { Test trench, secondary deposits } \\
\text { discarded by grave looters, on an } \\
\text { eroded natural silt bank }\end{array}$ \\
\hline V & $\begin{array}{l}\text { Flat area at the eastern } \\
\text { end of the Main } \\
\text { Mound }\end{array}$ & $\begin{array}{l}\text { Non-datable truncated living floors, } \\
\text { below eroded surfaces with early } \\
\text { Islamic to Seljuq pottery }\end{array}$ \\
\hline VI & $\begin{array}{l}\text { Main Mound, edge of its } \\
\text { steep eastern slope }\end{array}$ & $\begin{array}{l}\text { Layers transformed by mudflow and } \\
\text { aeolian activity, rich in chert debitage } \\
\text { of the 3rd millennium BC }\end{array}$ \\
\hline VII & $\begin{array}{l}\text { Varamin period } \\
\text { graveyard, eastern } \\
\text { side }\end{array}$ & Excavation of Grave 2, Varamin period \\
\hline VIII & $\begin{array}{l}\text { Main Mound, northern } \\
\text { slopes }\end{array}$ & $\begin{array}{l}\text { A living surface of the Konar Sandal } \\
\text { South period, with large pits full of } \\
\text { ashes and charcoal }\end{array}$ \\
\hline IX & Main Mound, top & $\begin{array}{l}\text { Test trench for geomorphological } \\
\text { sampling, paleosoil on a bank of } \\
\text { natural silt about } 4 \mathrm{~m} \text { deep, to be } \\
\text { dated }\end{array}$ \\
\hline$X$ & Jasper Mound & $\begin{array}{l}1 \times 1 \mathrm{~m} \text { square trench, for inspecting } \\
\text { the upper stratigraphy of the dumps } \\
\text { with jasper debitage }\end{array}$ \\
\hline
\end{tabular}

Note: For the chronological labels see Figure 6 and following text.

Trench II was excavated on the southern slopes of the same mounded area. It brought to light Grave 1, a well preserved "catacomb"-like grave dated, on the basis of the style of the pots, to the same general period. ${ }^{19}$ In February 2019, Trench III, in the southern edge of the site, explored one of earliest settlement cores. Trenches IV and VII were opened in the north-eastern part of the site. Here, the first operation exposed the natural soil, while in Trench VII came to light Grave 2, another large catacomb grave coeval to Grave 1, and equally rich in offerings (at present, in the course of restoration and documentation). The style of the black-on-buff ceramics with geometric patterns of the two graves, again, was very similar, as it was coherent with the sherds generally linked with the life and abandonment of the massive building exposed on top of the Main Mound.

Trenches V, VI and VIII were dug in the centre of the site, west of the Main Mound. In the first two locations,

\footnotetext{
${ }^{16}$ At Mahtoutabad, layers with Uruk-related pottery covered others with Aliabad ware, in turn found above $1 \mathrm{~m}$ thick deposits of a different, earlier early Aliabad or Mahtoutabad I ware: see Desset et al., "Mahtoutabad III (Province of Kerman, Iran)" and Vidale and Desset, "Mahtoutabad I (Konar Sandal South, Jiroft)."

${ }^{17}$ Eskandari et al., "A Late 4th to Early 3rd Millennium BC Grave in Hajjiabad-Varamin."

${ }^{18}$ Respectively Caldwell, Excavations at Tal-i Iblis; Prickett, Man, Land and Water; Sajjadi, "Prehistoric Settlements in the Bardsir Plain"; for Shahdad, Eskandari, "Excavations at the Prehistoric Sites of Tepe Dehno and Tepe East Dehno" and "A Reappraisal of the Chronology of the Chalcolithic Period in SE Iran"; wider discussion by Petrie, "'Culture', Innovation and Interaction" and "The Chalcolithic in southern Iran." See also Mutin, "Ceramic Traditions and Interactions" and Mutin et al., "New Discoveries in the Bampur Valley," who at any rate do not clearly distinguish between Mahtoutabad I/Early Aliabad ware and its later evolution of the 4th millennium $B C$.

${ }^{19}$ On Grave 1, see Eskandari et al., "A Late 4th to Early 3rd Millennium BC Grave in Hajjiabad-Varamin."
} 


\section{KERMAN}

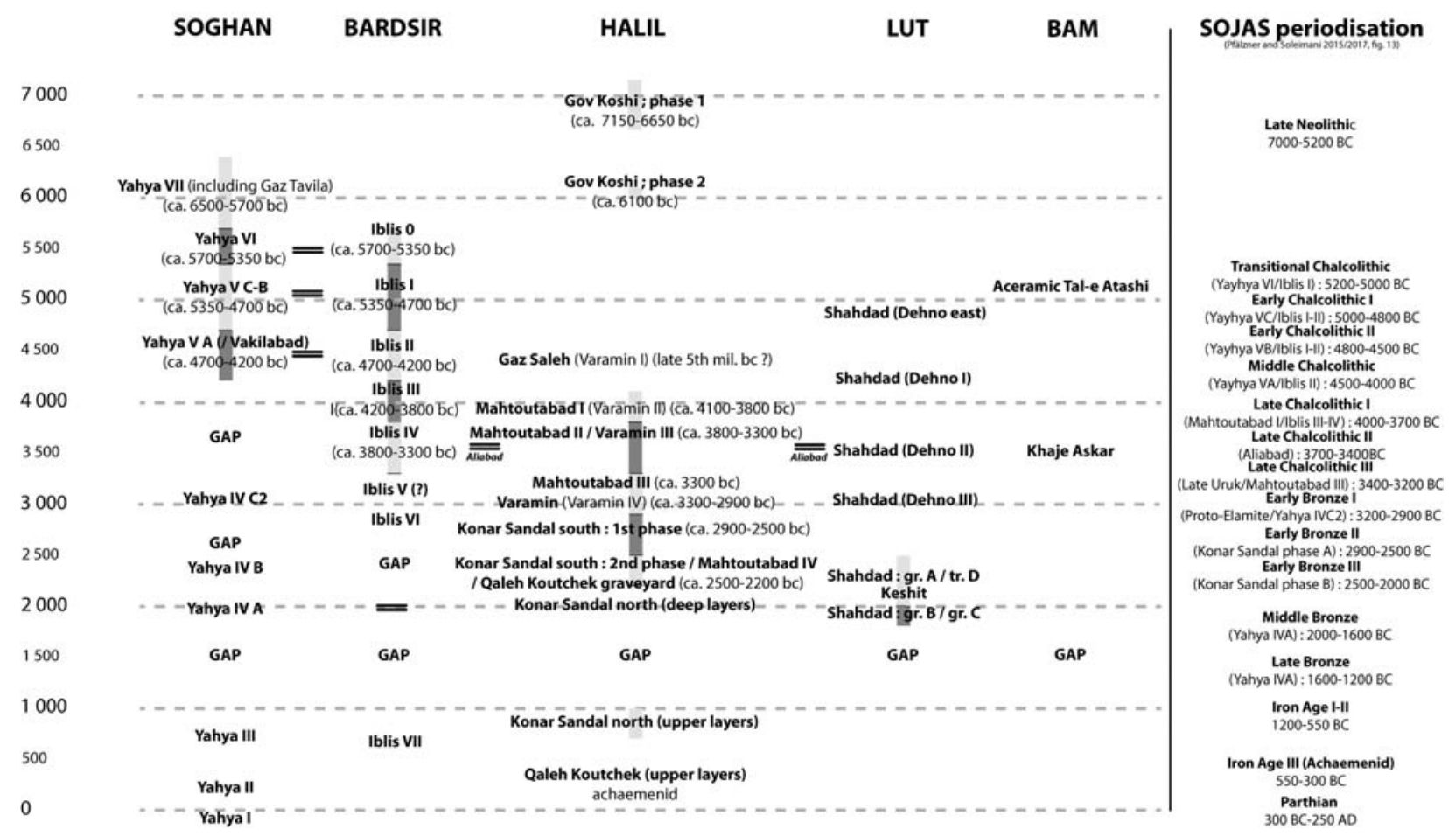

Figure 5. General archaeological chronology of the province of Kerman.

archaeological deposits were $40-60 \mathrm{~cm}$ thick. In Trench VIII, a better preserved stratigraphy included living surfaces and pits of the mid-3rd millennium BC, currently in course of study; the virgin soil was not reached. Trench X, finally, partially explored the uppermost layers of a mound at south-east, dating to the Islamic period (more details in the specific sections below).

In the same year, an intensive survey of the archaeological area allowed a better understanding of the growth of the settlement between the late 5th and the 3rd millennium $\mathrm{BC}$, the crucial formative stages of the Halil Rud civilisation. A total scrutiny of the surface by systematic transects (west-east parallel walks by two to three persons, in a boustrophedon fashion, at intervals of $20 \mathrm{~m}$ ) and a very limited, selective collection of artefacts from surface were added to ground testing (Figure 3). Aerial imagery, sampling for soil micromorphology (samples in the course of being shipped and processed) and ground penetrating radar (GPR) measurements (results to be verified by more testing trenches) were also applied and tested on the field.

\section{Periodisation and Sequence of Occupations}

In this article, we follow the regional periodisation of Figure 5, which integrates the preliminary results of the above-descripted fieldwork with old and new data, including a recent re-assessment of the absolute and relative chronology of the Chalcolithic period of south-eastern Iran after new $14 \mathrm{C}$ datings and digs. ${ }^{20}$ Figures 6-8 describe the transformations of the site through the various periods and diverse loci of occupation, based on the above listed Trenches and surface evidence.

- As remarked by the SOJAS team, ${ }^{21}$ no Neolithic ceramic assemblages, of the kind brought to light by N. Soleimani at Gov Koshi in the plain of Esfandagheh ${ }^{22}$ were so far reported in the Jiroft plains. Besides remains of the Palaeolithic period, the earliest occupations ever found go back to the mid-5th millennium BC (Yahya VA ware), while more ancient material dating back to Yahya VC/VB (late 6th-early 5th millennium BC) were found more in the south in the plains of Faryab and Rudbar. At Hajjiabad-Varamin such wares are

\footnotetext{
${ }^{20}$ For the chronological sequence of Tepe Yahya, in part diverging from the traditional ones (re-calibrated dates for Yahya VA at Tepe Yahya and Muradabad, in Voigt et al., "The Chronology of Iran") we refer here to new evidence already published in Shafiee et al., "Gahnegari nesbi va motlaq Tappeh Vakilabad Ourzouyeh."

${ }^{21}$ Pfälzner and Soleimani, "The ICAR - University of Tübingen South-of-Jiroft Archaeological Survey"; Pfälzner et al., "SOJAS 2015-2018: A Résumé of Four Seasons," 111.

${ }^{22}$ Soleimani and Fazeli Nashli, "Gahnegariye dorehye no-sangiye Kerman."
} 



Figure 6. Map of the occupations recorded for the Gaz Saleh (a), Mahtoutabad I/Early Aliabad (b) and Aliabad periods (c).
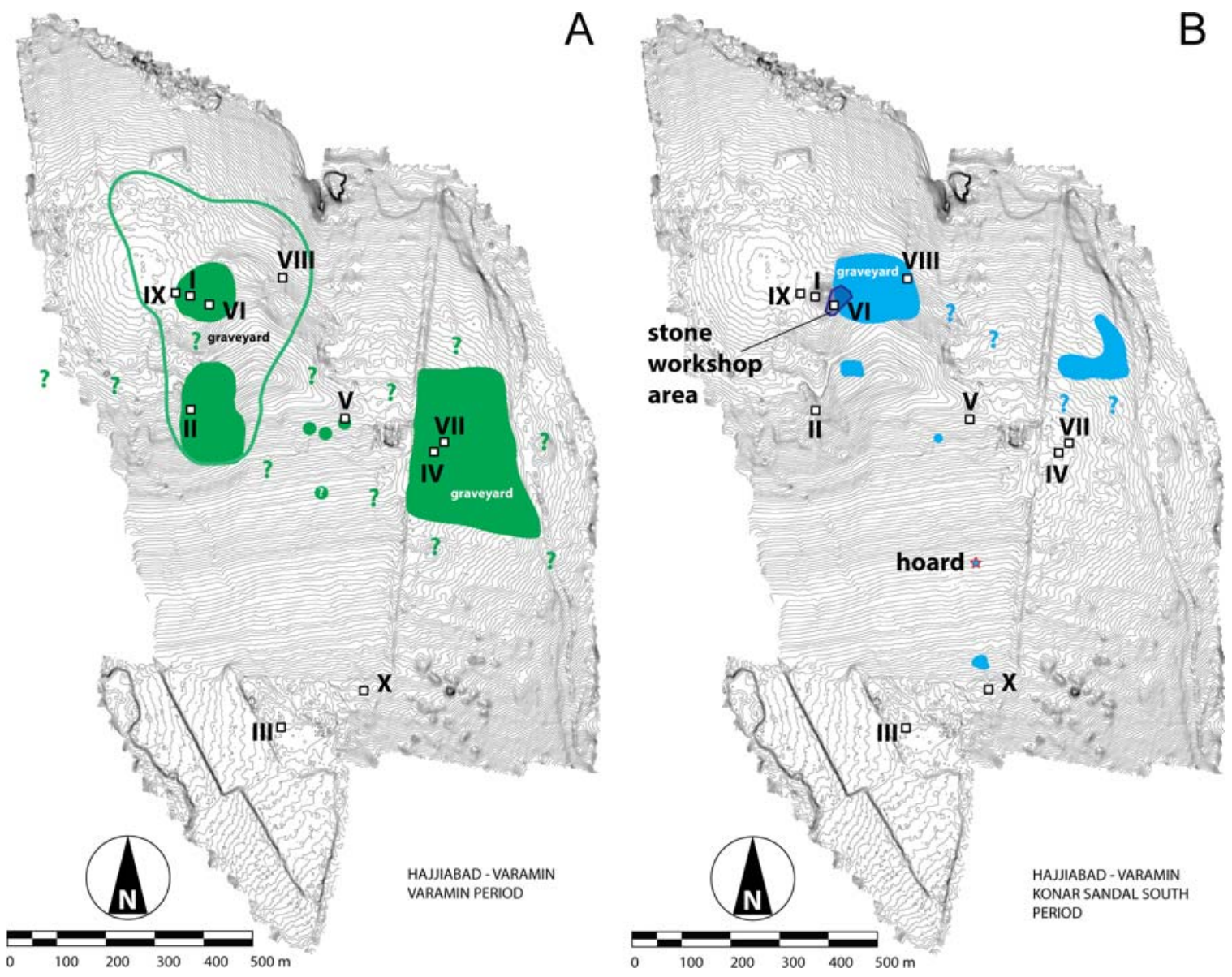

Figure 7. Map of the occupations recorded for the Varamin (a), and Konar Sandal South (b) periods. 

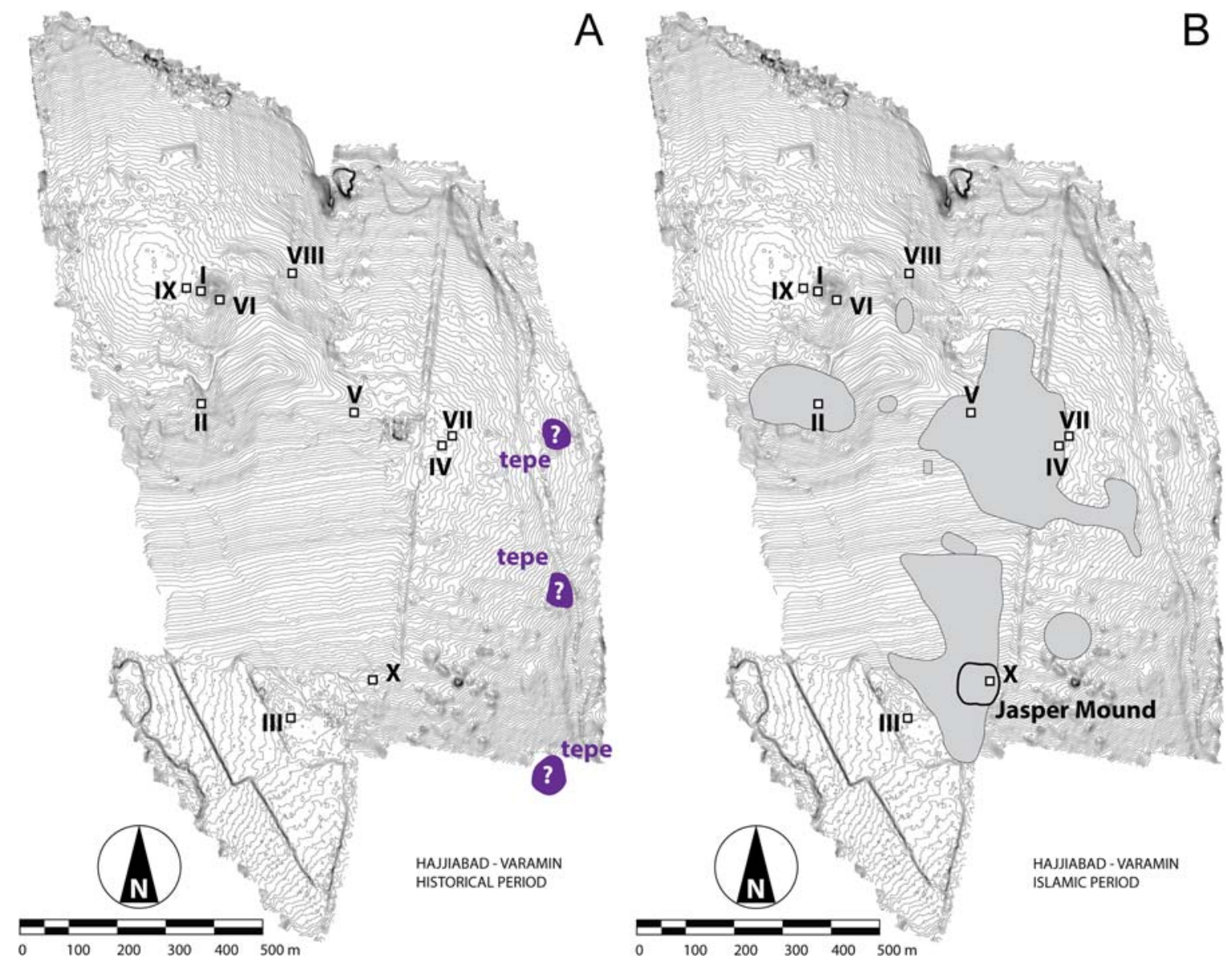

Figure 8. Map of the occupations recorded for the historic (a) and Islamic (b) periods.

absent, and there is no evidence of the Yahya VA Blackon-Red slipped pottery datable to the mid-5th millennium BC.

- Gaz Saleh period (2nd half to the late 5th millennium BC; see the chronological-cultural frame in Figure 5). The settlement of Hajjiabad-Varamin seems to have started as a small inhabited core, whose people used a distinctive pottery we shall describe below for the first time. Such earliest occupation took place south of the wide levelled area visible in the centre of the map of Figure 3 and as red spots in Figure 6(a). Here, on the surface of a low mound marginally damaged by recent earthworks, for an extension of no more than 1-1.5 ha, we collected, together with a certain number of Mahtoutabad I/Early Aliabad ceramic fragments, ${ }^{23}$ sherds belonging to a different earlier assemblage, which we preliminary named "Gaz Saleh" after the nearby village south-east of the site. Trench III $(5 \times$ $3 \mathrm{~m}$ ) revealed below the surface, for a depth of 30 $40 \mathrm{~cm}$, a sequence of loose layers disturbed by aeolian activity and probably old ploughing surfaces; a shallow pit, dug in the local bank of natural silt, contained the large complete bowl of Figure 9(f). The pottery, in Figures 9 and 10, represent the Gaz Saleh assemblage, stratigraphically earlier and different from the Mahtoutabad I/Early Aliabad one.

The pots of this assemblage are generally finer and more compact in texture than those of Mahtoutabad I and display large dark brown bands painted on buff backgrounds, sometimes over-painted with simple white traits. On record are thin-walled hemispherical or truncated cone-like bowls or basins, unpainted (Figure 10(a-f)); tall, fine truncated cone-like beakers similar in shape to those of the following Mahtoutabad I/Early Aliabad and Aliabad periods (Figure 9(g-o)), some with peculiar, large multiple-toothed swastikas (Figure 9(l,n)). Among the closed forms there are large, sub-cylindrical to globular pots or small jars with pointed rims, plain, more rarely painted brown or black with large external friezes (Figure 10(a-h)). There are also globular "cooking pots" with narrowed mouth that, differently from those of Mahtoutabad I/

${ }^{23}$ As described in Vidale and Desset, "Mahtoutabad I (Konar Sandal South, Jiroft)." 

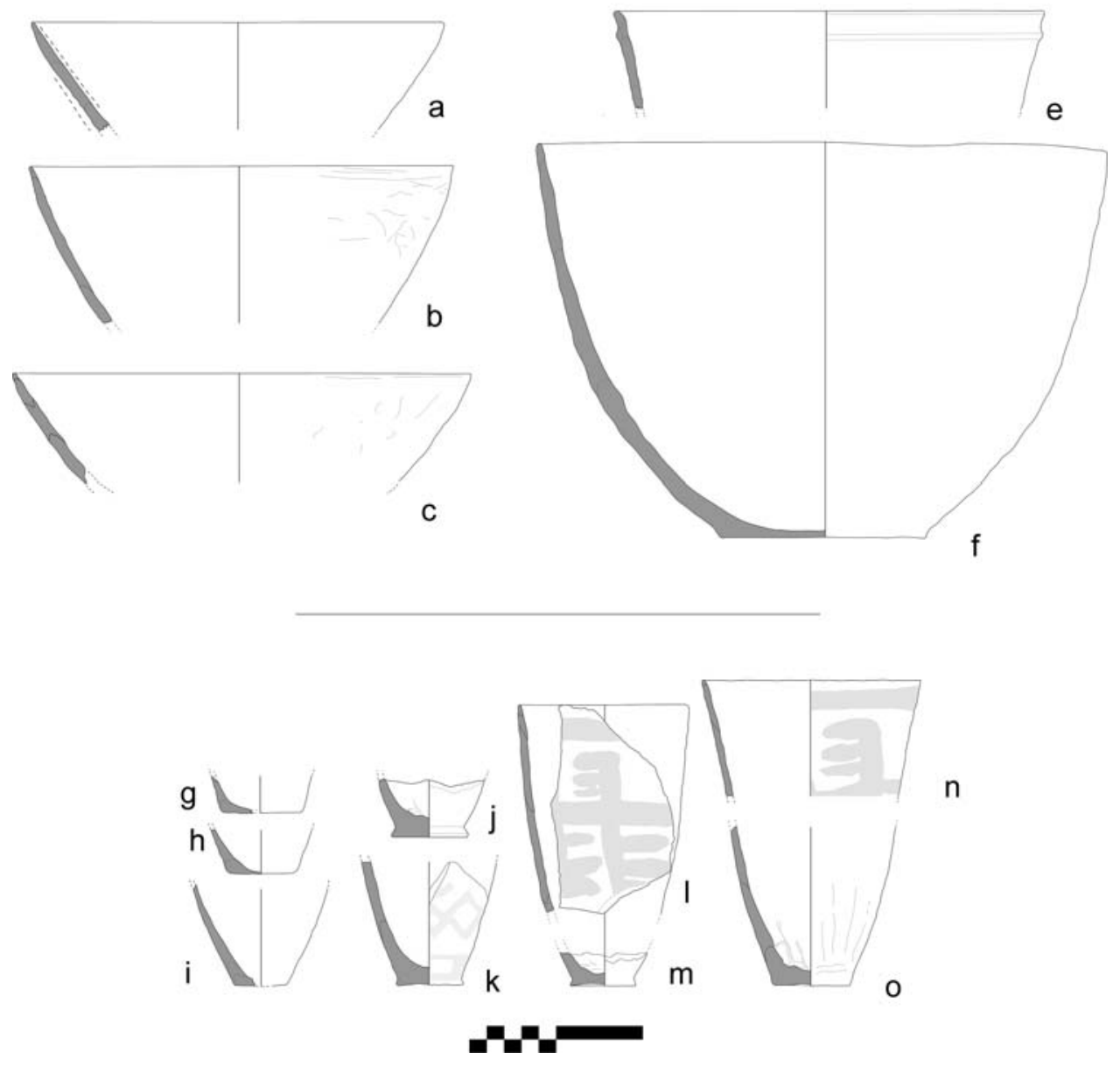

Figure 9. Hajjiabad-Varamin. Pottery of the Gaz Saleh period, open forms. In this assemblage the ridges of the flanged wares are absent or minimally emphasised (like in (e)). Tall beakers $(k-0)$ are painted with thick brushstrokes in dark brown pigments, almost vanished.

Early Aliabad lack the usual applied ridge in relief which distinguishes the flanged wares (Figure 10(i-k)), and larger unpainted jars with a short rounded, everted $\operatorname{rim}$ (Figure 10(1-m)).

- Mahtoutabad I/Early Aliabad ware period (late 5thearly 4th millennium BC). The brightly coloured Mahtoutabad I pottery of this period was found for the first time $4 \mathrm{~m}$ below the present day surface in the deepest explored levels of the plundered graveyard of the same name. ${ }^{24}$ While at Hajjiabad-Varamin only three sherds were reported by the SOJAS team, ${ }^{25}$ this pottery (Figure 11) is probably more abundant in HajjiabadVaramin than previously expected.

It is easily recognised because of the wide variety of designs in contrasting colours (orange, purple to black and white on pinkish red backgrounds). Previously dated at Mahtoutabad by four radiocarbon samples to the period 4200-3800 BC (carbon fragments from a micro-stratified sequence of superimposed floors of the same building), ${ }^{26}$ this ware was quite technologically advanced, being finely formed with coils shaped on a potter's wheel, or coiled within large moulds, than carefully thinned by vertical trimming on the exterior, while the foot was later added to the upturned vase revolving on the potter's wheel. Finally, pots were painted in a wide variety of dark purple, red-orange and white patterns on pinkish-red biscuits. The chaine opératoire of this production is currently under archaeometric study at the labs of the University of Padova.

\footnotetext{
${ }^{24}$ Ibid.

${ }^{25}$ Pfälzner and Soleimani, "The ICAR - University of Tübingen South-of-Jiroft Archaeological Survey," 127.

${ }^{26}$ Vidale and Desset, "Mahtoutabad I (Konar Sandal South, Jiroft)," 247 (four calibrated dates).
} 




Figure 10. Hajjiabad-Varamin. Pottery of the Gaz Saleh period, closed forms. (a) and (c-e) are painted with thick brushstrokes in vanished dark brown pigments; (h) a globular jar, bears two parallel oblique lines painted in white across the body.

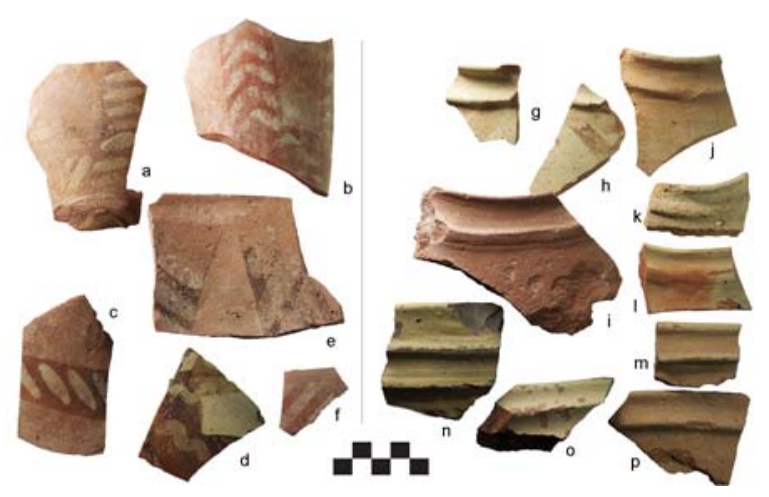

Figure 11. Hajjiabad-Varamin. Mahtoutabad I/Early Aliabad period painted beakers $(a-d)$, bowls $(e, f)$ and flanged ware (g-p). Flanged jars are usually unpainted, but some, like (g) and (h), are painted brown with large diagonal strokes.

The forms of this ware include hemispherical bowls painted on the interior (Figure 11(e)); fine truncatedcone-like beakers on disk bases $((a-c)$ in the same Figure), unpainted globular pots with narrowed mouths and sharp ridges in relief (flanged jars $(g-p)$ ), perhaps used for cooking. Flanged ware also includes a variety of large truncated cone-like unpainted bowls and basins, and large subcylindrical jars, with one or more well-

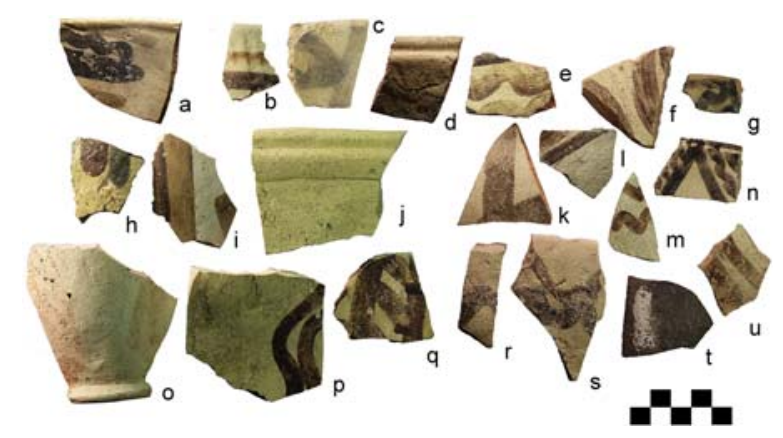

Figure 12. Hajjiabad-Varamin. Aliabad painted sherds. The pottery of this period gets thicker, and the colours shift from redorange to buff-green; the pigments are now shades of brown, variously diluted, and white.

fashioned ridges in relief, applied under the rim. Large jars, too, may be painted with fast brushstrokes in broad geometric patterns.

In the southern part of the archaeological area, sherds of Mahtoutabad I/Early Aliabad type were found on eroded surfaces together with Aliabad ceramics, above the excavated layers containing Gaz Saleh materials. Other apparently isolated sherds of the same kind were observed on the slopes of the main mound in the north, and nearby Trench V (Figure 6(b)). Their distribution, considering the stratigraphic position, suggests a gradual expansion of the settlement towards north.

- Aliabad ware period (3800-3300 BC). The Aliabad pottery (Figure 12) is actually a development of the Mahtoutabad I/Early Aliabad technical tradition: while many basic forms and templates are rather similar, some forming and painting techniques are simplifications of older ones. For example, the flanged ridges applied on the Mahtoutabad I bowls became less prominent (like in Figure 12(j) or were just replaced by a blunt groove below the outer rim, as in (d)).

Aliabad pots are usually sturdy, painted with gross but highly visible bichromatic patterns (black to brown and light brown, this latter made with diluted paint, see Figure 12(a,i)), in a limited set of crude geometric designs traced in liberty with large brush strokes (metopes, circles, thick wavy and stepped lines, festoons, stars). Vessels were also frequently painted white, particularly when darker lines and panels were filled with thick round dots (Figure 13(b)). The sturdy ring feet (Figures 12(o) and 13, overfired specimens) of these distinctive tall conical goblets, resistant to destruction, are excellent chronological markers of their horizon also on surface.

Pots were fired in incomplete oxidising or reduced conditions, resulting in pale buff to greenish hues. In the centre of the site we found a deeply eroded craft area (about $20 \times 20 \mathrm{~m}$ ) which had hosted at least two 


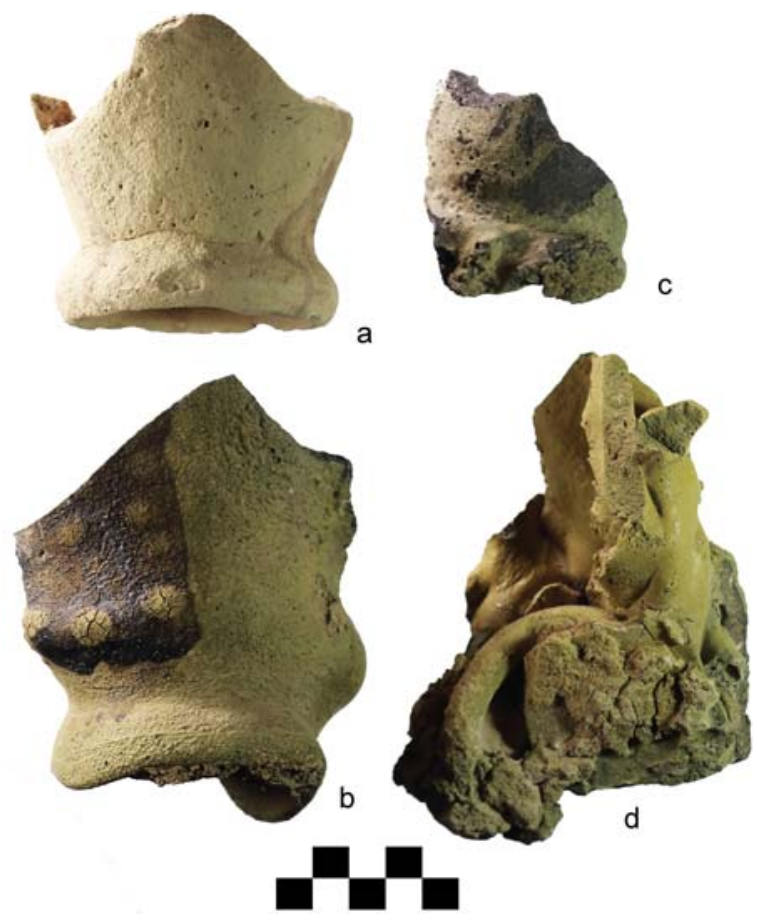

Figure 13. Hajjiabad-Varamin. Fragments of Aliabad period conical beakers, warped by firing accidents, found in the kilns area in the centre of the site. The pottery became sintered and olivegreen, with glassy surface. Most probably these beakers were serially mass-produced.

or three ceramic kilns abandoned after firing accidents (Figure 6(c)). The whole surface was littered with stone artefacts and waste flakes, slags and overfired fragments of conical goblets warped by firing accidents (Figure 13). Still standing in situ on the eroded floor of a kiln, we picked up was a tiny, overfired bull-shaped token or figurine, $3 \mathrm{~cm}$ long.

Aliabad ceramics of this description, easily recognisable on surface, mark an expanded occupation of the site during the central centuries of the 4th millennium BC. Two different areas are strewn with such pottery. The first, in the centre of the archaeological area, looks like a chain of discontinuous small, low mounds surrounded by erosive channels, extending from the slopes of the main mound towards south-east.

Even including the basal area of the main mound, which cannot be observed, this first area bearing Aliabad ware cannot extend more than about $500 \times 300 \mathrm{~m}$, i.e. at maximum 15 ha. At south, the surface, as stated above, had been levelled by agricultural earthworks, and cannot be evaluated. However, the general topography, the outcropping natural soil and the absence of prehistoric pottery in the damaged surfaces, as well as in the dirt piled nearby, would exclude that this part of the site hosted important settled compounds. The second remaining Aliabad cluster (about $100 \times 200 \mathrm{~m}$, 2 ha maximum) was found in the described low mound in the southernmost extent of the site, associated with Gaz Saleh and Mahtoutabad I sherds (see ceramics in Figures 11 and 12, collected on the surface of Trench III).

- Varamin period (late 4th-early 3rd millennium $\mathrm{BC})^{27}$ (Figure $7(\mathrm{a})$ ). With the publication of Grave 1 (as stated above, exposed in Trench II), ${ }^{28}$ and the following dig of Grave 2, this latter in course of study both large catacomb burials with more than 90 objects each - we came to use such label for a very important, albeit still partially unclear, occupation of the site of Hajjiabad-Varamin. At the time, the place hosted in the northern half an important cemetery which, judging from the scattered sherds, encompassed not less than 25-30 ha. The nearby cemetery of Rig Anbar (4 km south-east), also extensively ransacked, clearly belongs to the same period.

The pots from Graves 1 (a sample in Figure 14) and 2, and those smashed on surface after the pilfering of dozens of contemporary graves (Figure 15), are mainly thick-walled containers: large bell-like bowls, hole-mouth and necked jars, and a limited repertory of finer bowls and beakers. Decorative motifs are painted with thick, solid brushstrokes. Designs are rather unimaginative and repetitive, but more regular and visually balanced than those of Aliabad ware: among these range chains of lozenges, triangles, crosses, festoons, and hourglass designs in metopes (repertory in the vessels of Figure 14), hatched or cross-hatched; less common are large bi-triangular, schematic ibexes (as in Figure 15(l)) or, in Grave 1, "fatty scorpions" (Figure 14(a,i)). Sometimes painters also resorted to simplified bi-chromatic (dark brown and orange) painted designs (Figure 14(d)). In Grave 1 the interior of two large bell-like bowls (Figure 14 $(\mathrm{d}, \mathrm{f}))$ was sprinkled with an oblique throw of paint droplets. This well distinguishable pottery represents an evident break with the previously continuous tradition of the late 5th-4th millennia BC. So far, on the dirt from the destroyed Varamin period graves

\footnotetext{
${ }^{27} \mathrm{Ibid} ., 128$, the authors report to have found Uruk-related materials on the surface of the site, but give no supporting evidence of this. Our survey did not reveal a single sherd of such description. As stated above, the Mahtoutabad III assemblage, as published by Desset et al., "Mahtoutabad III (Province of Kerman, Iran)," also includes some sherds of vessels painted in the same simplified graphic tradition, and the Varamin Period pottery we present here has obvious connections with part of the Yahya IVC Black-on-Buff wares, as described, for example, in Lamberg-Karlovsky and Potts, Excavations at Tepe Yahya, Figures 1.12,1.18.A, 2.12.B and E., 2.15.A and some other specimens in Figures 2.22-25.

${ }^{28}$ See Eskandari et al., "The Formation of the Early Bronze Age Jiroft Culture."
} 


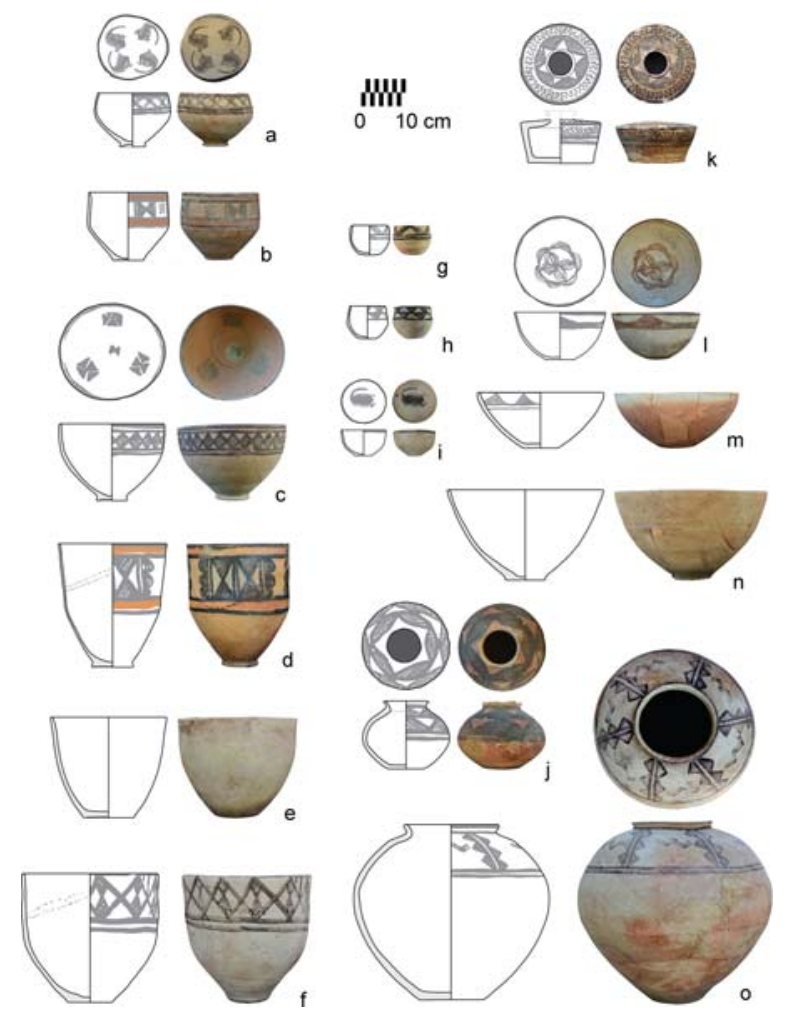

Figure 14. Hajjiabad-Varamin, a sample of the ceramic furnishing of Grave 1 may illustrate the pottery of the Varamin period. (a) G1.46; (b) G1.49; (c) G1.55; (d) G1.30; (e) G1.17; (f) G1.5; (g) G1.79; (h) G1.80; (i) G1.50; (j) G1. 28; (k) G1.54; (l) G1.32; (m) G1.35; (n) G1.74; (o) G1.2. The conical canister jar k seems to be an import or a local version of a Nal pot, stylistically ascribed to central Baluchistan and datable to 3100-2900 BC (Franke and Cortesi, Lost and Found, 145-7). The grey ware bowl (I), painted in deep brown/red, belongs to an eastern production abundantly represented in a recently published grave from the site of Spidej (Heidary et al., "A Late 4th-Early 3rd Millennium BC Grave at Spidej"), in eastern Jazmurian, dated to the same period.

we found no evidence of vessels or other carved objects in chlorite.

On the top of the Main Mound, the monumental mudbrick building that had been partially exposed by Trench I seems to fall chronologically between the end of the Varamin occupation and the following one (mid-3rd millennium BC). The function of the building and its relationships with the nearby funerary lots at present remain open questions: we have part of a major building and an extensive cemetery but, for the moment, the possible settlement is still elusive. The occupied areas seem limited to a strip of isolated

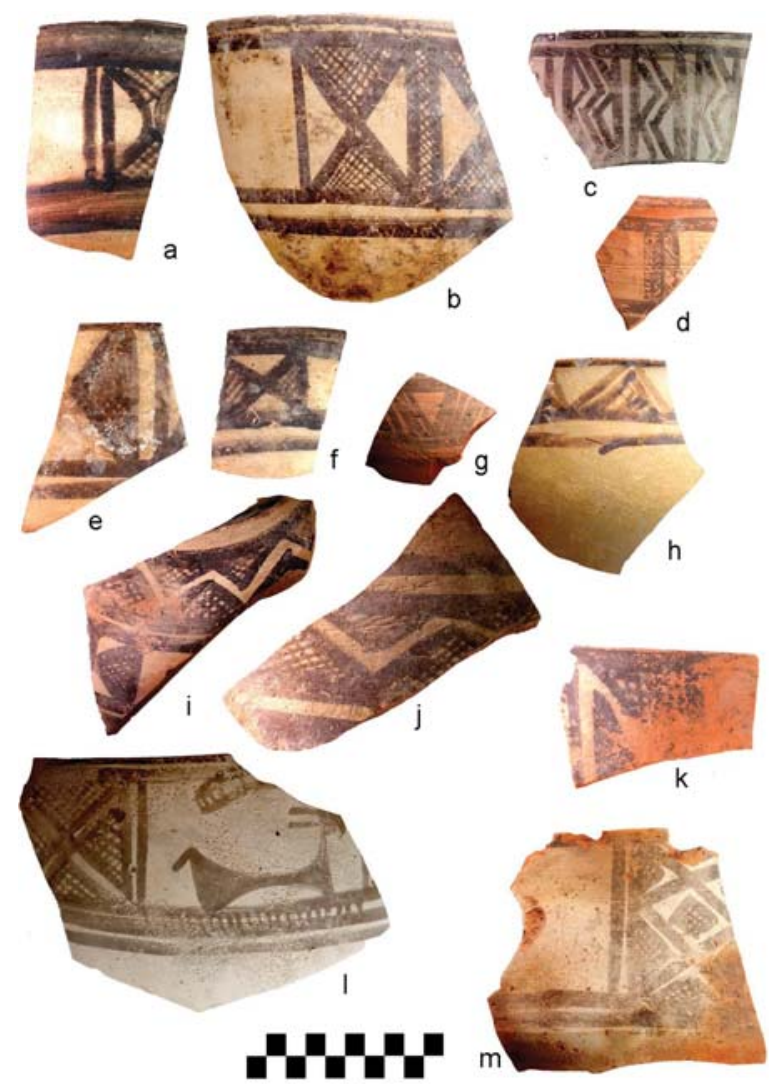

Figure 15. Hajjiabad-Varamin, large sherds coming from plundered graves of the Varamin period.

locations along the northern edge of the Varamin period graveyard, and to few other spots at south.

- Konar Sandal South period (Figure 7(b)): second and third quarters of the 3rd millennium BC. This period, apparently an apex of the early urban civilisation in the Halil Rud basin, ${ }^{29}$ is distinguished by wheelthrown plain and red-slipped ceramics, sometimes finely painted black-on-red (Figure 16), mostly found in illegally excavated graves and dumped with the dirt near the pits. The designs are those common in the contemporary ceramic repertories: among others, multiple zig-zag friezes, festoons, lozenges, comb-like features, rows of sigmas, slender ibexes with round emphasised horns. ${ }^{30}$ Abundant, in these secondary assemblages, are fragments of large unpainted jars with wavy ridges on shoulder (Figure 16(m-o)). Similar jars were previously found at Konar Sandal South and Mahtoutabad IV (still unpublished). They were also recorded in the later cemetery of Chegerdak in the Jazmurian basin, and obviously in Tepe Yahya IVB. ${ }^{31}$

\footnotetext{
${ }^{29}$ Madjidzadeh and Pittman, "Excavations at Konar Sandal."

${ }^{30}$ See, for examples, ibid., figs. $22-4$.

${ }^{31}$ See Heidary et al., "A Surface Collection at Chegerdak" (fig. 12, 34, and 15, 42, both painted), comparable with jars from Bampur III, in De Cardi, Excavations at Bampur, figs. 22 and 23. The mentioned unpainted jars with wavy ridges appear in Lamberg-Karlovsky and Potts, Excavations at Tepe Yahya, Iran 1967-1975, fig. 4.31. For Konar Sandal South, Madjidzadeh and Pittman, "Excavations at Konar Sandal," fig. 22.
} 


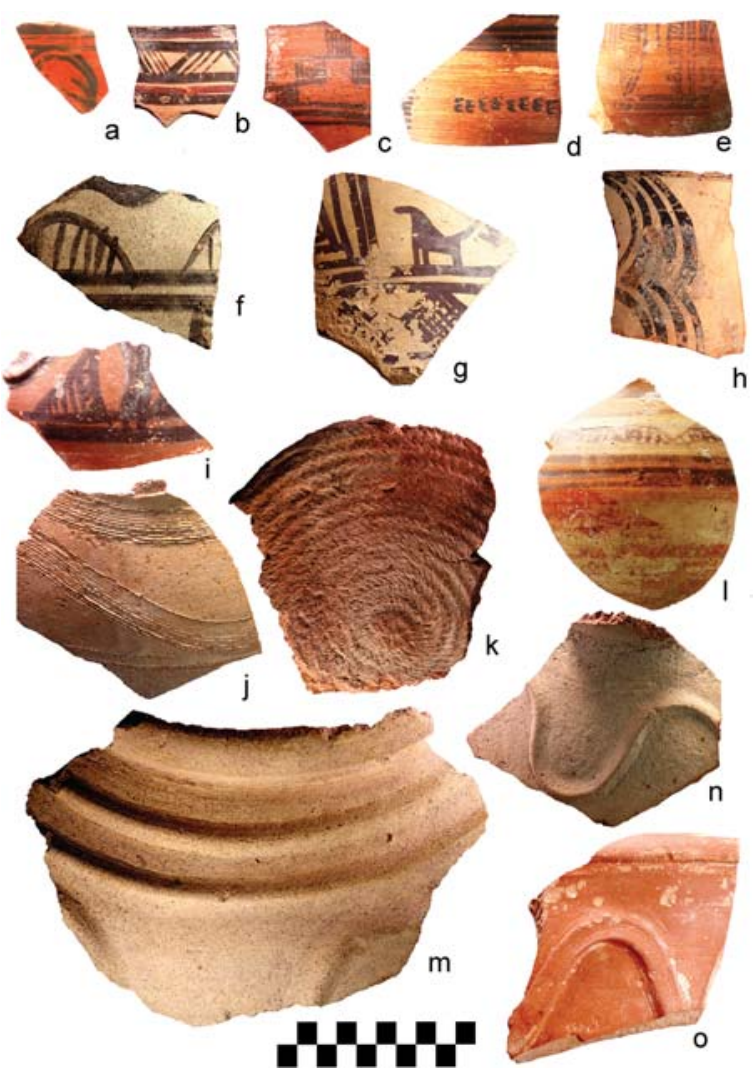

Figure 16. Hajjiabad-Varamin, large sherds gathered at the site of the plundered graveyard of the Konar Sandal South period in the western slopes of the Main Mound. (a-j) and (I) show some of the most common painted designs of the mid-3rd millennium BC is eastern Iran. ( $k$ ) also coming from a destroyed grave, is the outer base of a thick jar built in a basket mould. $(m-0)$ are shoulder fragments of other jars with plain wavy ridges in relief.

In Hajjiabad-Varamin, many mid-3rd millennium BC sherds, fragmented in tiny bits, are also widely scattered on surface in the north-eastern side of the site, and, at least in part, might come from buried settlement layers. On surface, it is not always easy to distinguish coeval and similar sherds from recently looted graves and those eroded from buried living surfaces. Actually, Trench VIII, dug at the eastern limit of the slopes of the Main Mound, revealed at a depth of about 0.5-1 m layers from a contemporary living surface, with utilitarian unpainted ceramics (presently in course of study). On the whole, the real extension of the Konar Sandal South occupation and precise relationships with its looted cemetery cannot be established from the disturbed surface alone; to state that the cemetery of this period was an "intra-urban burial area" is probably premature. ${ }^{32}$

Based on the lithic waste, an important stoneworking area was recognised in this same location. ${ }^{33}$
At a preliminary evaluation, the pottery visible on surface seems to range from about $3700 \mathrm{BC}$ to the second half of the $3 \mathrm{rd}$ millennium BC. The surface is presumably a washed-off palimpsest in which - as stated above - artefacts of at least three subsequent periods of occupation have been piled together. Of course, given the established comparisons, it is the lower chronological term that may be hypothetically linked to the craft area.

- Early historic and Islamic periods. So far, the only evidence of a possible early historic settlement was detected in a series of low mounds visited on the eastern margin of the site (Figure 8(a)). Their precise chronology and kind of occupation are matters for future investigations. Much more substantial is the evidence of an early Islamic habitational period.

In fact, the entire central portion of the HajjiabadVaramin site hosts the remains of a large Islamic settlement datable - according to the preliminary evidence of the artefacts spread on surface - to the ninth-thirteenth centuries $\mathrm{AD}$, at the time of the main occupation of the old city of Jiroft, just south of the modern twentieth century settlement. Some abi o sefid (blue and white) decorated ware could be attributed to the fourteenth and fifteenth centuries AD. The site seems to have expanded about $700 \mathrm{~m}$ from south to north, and $1 \mathrm{~km}$ or more west to east; it might have covered an extension of c. 35-40 ha. In its westernmost edge, among contemporary fields irrigated by Qanats and ducts of unknown age (visible on aerial pictures outside the limits of the map), are visible the ruins of important buildings in fired bricks, widely eroded and heavily affected by saline efflorescence, and few large kilns studded with overfired and warped bricks and ceramics. Fragments of moulds for stamping small containers with intricate decorative patterns in relief, and sometimes inscriptions, indicate the presence of potters also in the centre of the mediaeval urbanised area. Traces of other craft activities (iron smiting and possibly glass working), are scattered west of the main road that bisects the archaeological area, between the local Police station and the Main Mound. Remnants of houses built in mudbricks, exposed by recent earthworks and dissected by weathering, are still visible 100-150 $\mathrm{m}$ south of the same house.

In the southern stretch of the settlement, a series of low mounds, heavily impacted by recent construction works and dumping, were covered by enormous amounts of small lumps of white quartzite, by cores and flakes of an attractive yellow, red and brown mottled jasper, and by flakes of an unidentified light

\footnotetext{
${ }^{32}$ Pfälzner and Soleimani, "The ICAR - University of Tübingen South-of-Jiroft Archaeological Survey," 124.

${ }^{33}$ Materials already noted and collected by the SOJAS project, see ibid., fig. 27.
} 
green rock. This "Jasper Mound", as it was called, is probably the only large scale raw materials storage and bead making site so far identified for mediaeval Iran. It would certainly deserve a dedicated study. A very limited Trench $\mathrm{X}$ revealed that the lithics are still embedded in dark brown, soft silty layers rich in organic inclusions, for an unknown depth; and that possibly among the beads produced in this industrial neighbourhood there were large, heart-shaped pendants with an upper apical suspension hole. As for the white quartzite pebbles, not suitable for making beads, the only hypothesis, at present, is that they could have been used as a raw material for making glass. This area, at present, is dated to the ninth and eleventh centuries AD by few green and blue-glazed sherds and a fragment of a distinctive bronze container. Near this important craft area, to the north-west, there were at least some graves whose only remains were pieces of terracotta gravestones with decorative patterns and parts of inscriptions in relief. It will be important to understand the links between this centre and a coeval settlement, protected by a square castle, recorded at Marjan-Varamin. ${ }^{34}$

\section{Stone-Working Area East of the Main Mound}

The stone-working area of the mid-3rd millennium $\mathrm{BC}$ is located on surface east of the slopes of the main mound (Figure 7(b)). It extends approximately $100 \mathrm{~m}$ (north west to south east) $\times 50 \mathrm{~m}$ in the opposite direction. It is probably the largest and more complex stone manufacturing site ever found in Bronze Age Middle Asia. It is worth to be excavated and deserves archaeometric investigation, on the line of previous important palaeo-technological studies. ${ }^{35}$

On the bases of the test trenches, we estimated that the surface, from the local slopes of the main mound eastwards, was eroded for an unknown depth, certainly more than $1 \mathrm{~m}$. Its surface is strewn with thousands of fragments of white banded calcite, to a great extent chipping waste and fragments of "alabaster" vessels broken and discarded while being shaped and drilled (Figure 17). The products were shaped into carinated rough-outs, with a coarse outer surface, then drilled, and only finally polished with care, both outside and inside. The white and translucent bands of the stone contrast with the rarer calcite vessels fragments found on the surface of the 4th millennium BC Aliabad locations, rather made of a darker green, brown-banded variety.

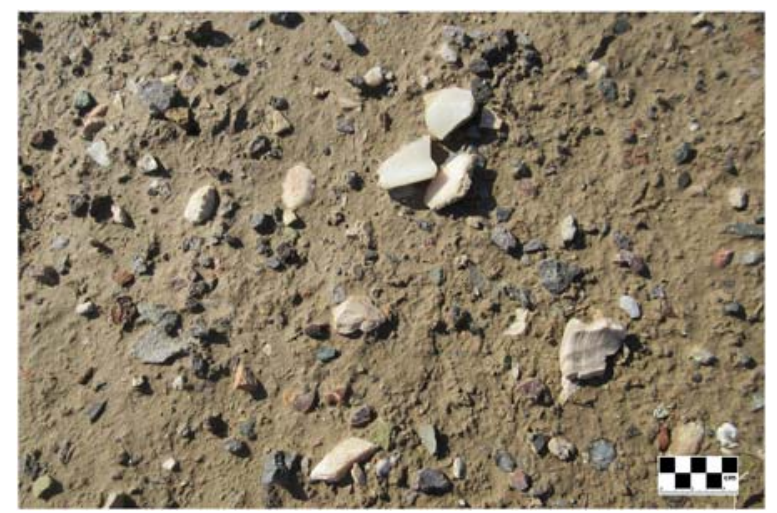

Figure 17. Hajjiabad-Varamin, western slopes of the Main Mound. A detail of the surface of the stone vessels manufacturing area (Konar Sandal South period): a cluster of fragments of white banded calcite vessels, probably broken while drilling, and other splinters.

The main semiprecious stone products represented on the surface record, and certainly manufactured in the site, are the following:

- small carinated vessels with a narrow base and flat projecting rim in white banded travertine. A minor amount of vases of this fashion was also made with varieties of a grey limestone spotted with the unmistakable white inclusions of the Waagenophyllum Permian corals; ${ }^{36}$

- tall cylindrical vessels with a flat projecting rim and a slightly tapered contour, made with banded travertine and limestone;

- vessels of less common types, always made with white banded travertine, including truncated-cone like bowls;

- thin walled, undecorated vessels in chlorite (bowls and other forms);

- rectangular beads with a sub-triangular section made with a green calcite, banded brownish red, systematically split in two during drilling.

Given their relevance for long-distance trade, particularly with Susiana, Mesopotamia and the Persian Gulf, each of these morphological classes is discussed in detail.

\subsection{Small Carinated Vessels with Narrow Bases and Flat Projecting Rims}

These vessels (Figure 18) correspond to M. Casanova's Series I as identified in the Susa

\footnotetext{
${ }^{34} \mathrm{Ibid}$., 133. We are very grateful to Dr. Amir Hajlu (University of Jiroft) for his preliminary identification of the ceramics found on surface.

${ }^{35} \mathrm{Ciarla}$, "The Manufacture of Alabaster Vessels"; "A Preliminary Analysis of the Manufacture of Alabaster Vessels"; "New Material in the Study of the Manufacture of Stone Vases"; "Fragments of Stone Vases as a Base Material"; Boccuti et al., "Preliminary Surface Analyses by ESEM-EDS of Calcite Bowls."

${ }^{36}$ Desset et al., "A Sculpted Dish from Tello."
} 

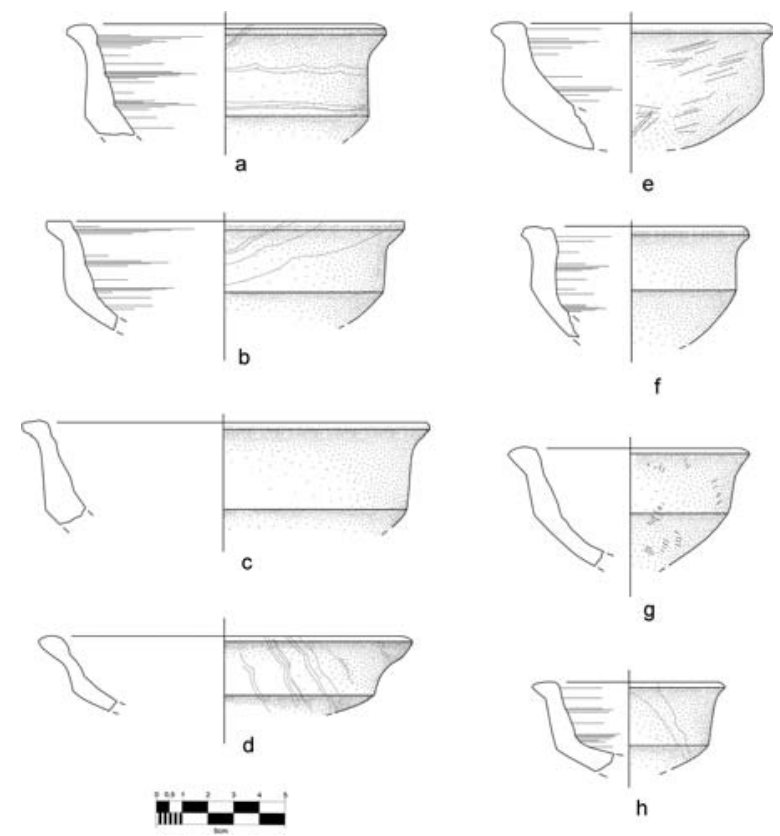

Figure 18. Hajjiabad-Varamin, western slopes of the Main Mound. A sample of white-banded carinated vessels' fragments found on the surface of the stone-working area. All show on the interior coarse drilling marks, suggesting that this was the operation during which the unfinished pieces broke down.

corpus. ${ }^{37}$ The most famous comparison for this class, due to the strongly carinated contour, narrow base and flat projecting rim, come from a large group of 110 precious objects found in the so-called vase à la cachette of Susa. $^{38}$ This heterogeneous assemblage is thought to reflect a network of trade contacts and cultural influence among Susa, Mesopotamia, Luristan, the eastern Iranian Plateau and Oman. On the base of cross-cultural stylistic comparisons it is dated to the Early Dynastic IIIB period, ca. 2500-2350 BC. This dating (particularly its lower limit) is plausible also because the graves of Shahr-i Sokhta, ${ }^{39}$ almost exclusively ascribed to the first half of the 3 rd millennium $\mathrm{BC},{ }^{40}$ contain mainly sub-cylindrical vases in banded calcite, but not such carinated form.

Figure 18 gives an idea of the range of formal variability of these vessels, although morphological details differ also in function of the execution of the

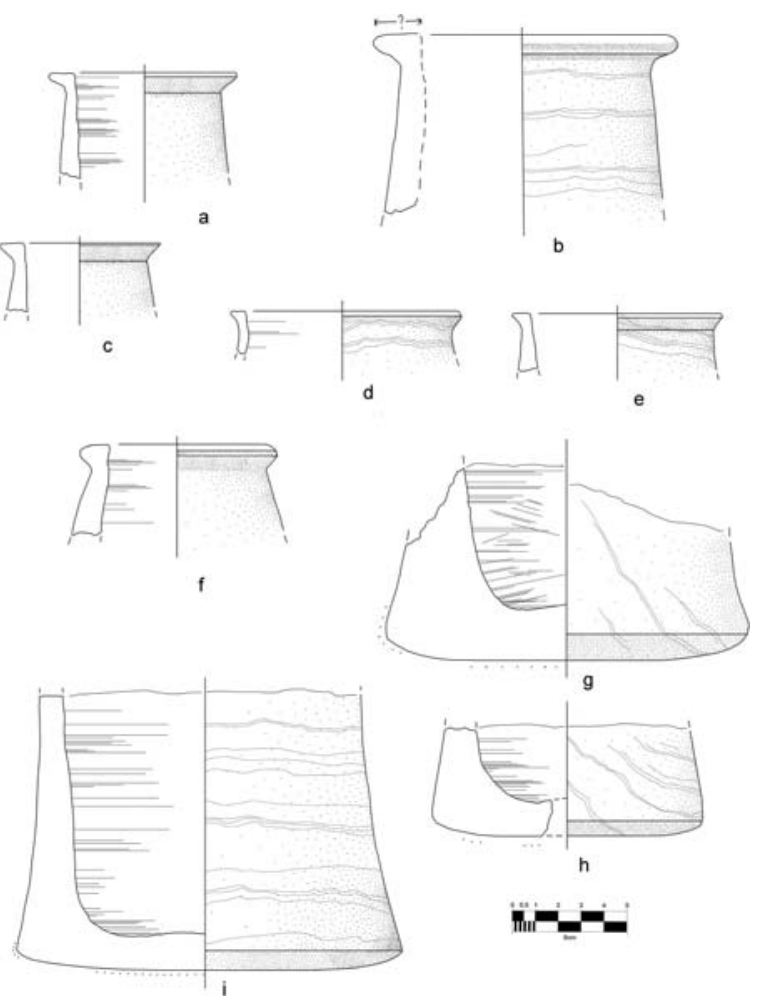

Figure 19. Hajjiabad-Varamin, western slopes of the Main Mound, craft area. A sample of white-banded cylindrical and perhaps sub-globular vessels' fragments found on the surface of the stone-working area. The outer surface of $(\mathrm{g})$ and $(\mathrm{h})$ is highly polished, suggesting that these pieces were finished pots, broken and brought to a workshop to be recycled.

manufacturing step responsible for breakage. Exactly like the one in the vase à la cachette, they were cut and drilled with the central axis at angles of $30-45^{\circ}$ to $90^{\circ}$ to the main parallel veins of the stone, which thus appear horizontal to oblique on the outer surface.

These vases were shaped and partially smoothed (but not fully polished) before being drilled. Several of the illustrated vessels show on the interior multiple coarse, uneven drilling rotatory marks; the sections are evidently too thick (with few exceptions); they suggest an incomplete drilling, and the lack of further smoothing of the interior.

\footnotetext{
${ }^{37}$ We report the comparisons for the type in Casanova, La Vaisselle d'Albatre de Mésopotamie, d'Iran et d'Asie Centrale, at page 32, note 34. First of all, Woolley, Ur Excavations, Vol. 2, PI. 177, U 7648, Tomb 12; PI. 245, types 54 and 55; Pl. 246, type 59. For Susa, de Mecquenem, "Offrandes de fondation du temple de Chouchinak," 11, figs. 399a and b; Le Breton, "The early periods at Susa," 118, fig. 40, $\mathrm{n}^{\circ}$ 7; for the vase a la cachette, Susa Dd, 120, fig. 42, ${ }^{\circ} 4$, Susa Da-De; Steve and Gasche, L'Acropole de Suse, 91-9, pl. 15, $\mathrm{n}^{\circ} 16$ = pl. photo 74, 2; Acropole, couche 3, end of the Proto-Dynastic period, 83, pl. II $\mathrm{n}^{\circ} 11$; Acropole, couche 2, early Akkadian period. For Shahdad, Hakemi, Catalogue de l'exposition Lut-Xabis, pl. XII, D, cat. 143, first half of the 3rd millennium BC; and Shahdad, various specimens from Cemetery A, 608-9. Among the Bactrian materials from looted graveyards, Pottier, Matériel funéraire, $\mathrm{n}^{\circ} 342$, fig. 28 and pl. LXIII. For Khurab, finally, Stein, Archaeological reconnaissances, pl. XXXII, 17 Bi. Casanova's datings, in this review (see Tableau 9 on chrono-typology), like that of Series IV, goes from 2600 to 1800 BC. Considering the general uncertainty on the precise dating of the pre-Akkadian graves of $\mathrm{Ur}$, the wavering chronology of the Shahdad cemeteries, and, of course, the Bactrian looted finds, a date within the twenty-fourth century BC - as proposed in Benoit 2003 for the vase à la cachette of Susa - would appear more likely. Actually, the type may have survived with variations for the whole last quarter of the 3rd millennium BC.

${ }^{38}$ Benoit, "Vase à la cachette."

${ }^{39}$ Piperno and Salvatori, The Shahr-i Sokhta Graveyard.

${ }^{40}$ See new chronological evidence in Kavosh et al., Tappeh Graziani.
} 


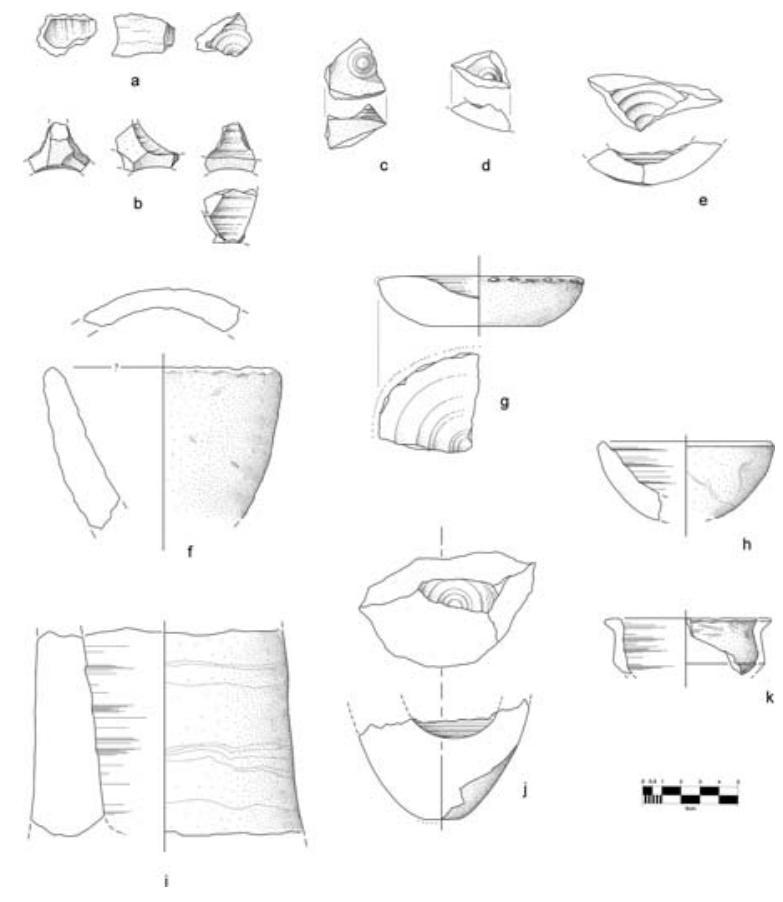

Figure 20. Hajjiabad-Varamin, western slopes of the Main Mound, craft area. Indicators of production of white-banded calcite vessels found on surface of the stone-working area: (a) and (b) stone lumps with holes drilled from different directions; (c) and (d) broken base fragments with a central conical lump; (e) rounded base fragment with marked drilling traces; $(f)$ a coarse travertine pot, with an eccentric mouth; (g) and (h) enigmatic objects, possibly used a tools (discussed in text); (i) and (j) body and base fragments with defective perforations; (k) a carinated vessel drilled to an excessive depth, resulting in the breakage of the base.

\subsection{Tall Cylindrical Vessels with a Slightly Tapered Contour and a Flat Projecting Rim}

Figure 19 shows forms corresponding to Susa's Series IV sub-cylindrical banded calcite vessels ${ }^{41}$ and are the second most common class in the craft context of
Varamin-Hajjiabad. They also represent the type most universally spread in protohistoric times: it is reported at Ur, Kish, Tello, Egypt, Bahrein, Shahdad, Kulli, Mundigak IV, in Bactria (and, we add, in the looted graves of the Jiroft area), in the same time range of 2600-1800 BC - always following the lists and tabulations of Casanova. The fact that some broken bottoms of this type (Figure $19(g-i))$, differently from the previous type, are strongly polished on the base and outer surface, and completely smoothed inside, suggests that the lower bodies of broken cylindrical vessels could be recycled in these workshops for the purpose of making new shorter containers. Comparisons would rather date the type (at least in the context we are discussing), between 2550 and 2350 $\mathrm{BC},{ }^{42}$ a date confirmed by its presence on the surface of Tappeh Graziani near Shahr-i Sokhta, together with contemporary ceramic assemblages. ${ }^{43}$

\subsection{Other Vessels Types Possibly on Record}

Some sherds of containers made of white banded calcite may belong to other forms, but their fragmentary status does not help in establishing their status of finished objects or production waste. Rarer are fragments of truncated-cone like bowls (like Figure 20(f) which however is in travertine, see below). Figure 20(c-e) fragments that might belong to a small subcylindrical container with a flat projecting rim and a very low corner near the base, might belong to the Susian Series IIa-IIb. Similar specimens appear in the pre-Akkadian graves of the Royal Cemetery of Ur (U 8126) and at Tepe Hissar IIIC (H 3615), pointing to a date, again, of 2600-1800 BC. ${ }^{44}$ Similar sub-cylindrical vessels were common on the surface of Tappeh Graziani, in contexts better datable to the first century of the second half of the 3rd millennium BC. ${ }^{45}$ The sherd of Figure 20(f) might have been part of a

\footnotetext{
${ }^{41}$ Casanova, La Vaisselle d'Albatre de Mésopotamie, d'Iran et d'Asie Centrale, 33, PI. 3, 41 and 46; PI. 4, 47-9, 169.

${ }^{42}$ Sub-cylindrical vases, with or without a slightly concave contour, are present, but not very common, in the furnishings of the Royal Cemetery at Ur (Zettler, Treasures from the Royal Tombs of Ur, cat. 128, p. 155, from Pu'abi's burial chamber, B17128, U.10921, and cat. 124, p. 153, from PG 1130, 30-12-698, U.11785). But the repertory of stone vessels of the Royal Cemetery is rather dominated by bowls and ovoid forms. In contrast, this type is quite common in the funerary assemblages looted in southern Bactria (Pottier, Matériel funéraire, 161, fig. 27, no. 205, 207, 208; 204, fig. 26; 207, PI. XXVl; Amiet, "Bactriane Protohistorique," fig. 7). The type is also well attested in Margiana at the necropolis of Gonur (Sarianidi, Necropolis of Gonur, 111, fig. 93, \# 717; see also Salvatori, Gonur-Depe 1, 6-7, who speaks of a "sub-cylindrical vessel with concave profile and everted rim ... in variegated alabaster"). The Gonur graves, and the Period Namazga V are now datable with confidence between 2350 and 2000 BC or later (ibid., and "Thinking around Grave 3245," this latter a general reassessment of all available absolute datings). Good matches are also identified at Altyn Depe (Masson, Altyn-Depe, burial 813, PI. XXV, 9a). These objects were common in the Halil Rud valley graveyards (examples in the Jiroft Museum, in Madjidzadeh, Jiroft: The Earliest Oriental Civilization) and in the Barbar temples of Bahrein (Glob, "Alabaster vases from the Barbar Temples," Fig. 2). For Shahr-i Sokhta, see the above mentioned Ciarla's papers and several examples in the graves (Piperno and Salvatori, The Shahr-i Sokhta Graveyard; Sajjadi, Excavations at Shahr-e Sukhteh, graveyard). Although a scientific chronological seriation of the graves is still wanted, the association of this type with diagnostic pottery dates it to Period III, now bracketed by 14C between 2600/2550 and 2450 BC. The inventories of Period III, phases 4-3, include some variants, tall or squat (Piperno and Salvatori, The Shahr-i Sokhta Graveyard, shows a squat version from Grave 712, Inv. No. 736, 253, Fig. 579; a better match in Grave 725 Inf., Inv. No. 8229, 278, Fig. 641; see also Sajjadi, Excavations at Shahr-e Sukhteh, graveyard, 414, 275, bottom). Grave 725 Inf. also contains typical ceramic forms of the Konar Sandal South period, thus linking both culturally and chronologically part of the plundered graveyards of the Halil Rud with the maximum early urban expansion of Shahr-i Sokhta. The type, in contrast, is completely absent in the Indus basin, in Shahdad's cemetery A (Hakemi, Shahdad, various specimens at pages 610-11) but was found in Shahdad cemetery B - a small group of 6 graves - probably datable to the second half of the 3rd millennium BC (ibid., 694, Ra 3, obj. no. 0370, from Grave 042, inv. 1/48).

${ }^{43}$ Kavosh et al., Tappeh Graziani, Fig. 13, 3.

${ }^{44}$ Casanova, La Vaisselle d'Albatre de Mésopotamie, d'Iran et d'Asie Centrale 33, PI. 2, 25, 27, 31, 33.

${ }^{45} 14 \mathrm{C}$ datings in Kavosh et al., Tappeh Graziani, figs. 10 and 13, 1, 2, 4, 5.
} 
small vessel with an ovoid body contour, perhaps a variant close to Casanova's Series $5,{ }^{46}$ like some chlorite flagons found in Cemetery A at Shahdad. ${ }^{47}$

\subsection{Additional Evidence of Local Manufacture of Stone Vessels}

Figure 20 shows some other surface finds from the above described stone vessels production area which might detail some aspects of the drilling process. Figure $20(a-b)$ are quite unusual indicators, in that they bear part of the holes left by multiple drilling episodes, and from different axes, on the same calcite blocks. These pieces do not belong to a recognisable rational manufacturing step. Perhaps craftsmen trained their drilling skill onto thick waste fragments, turning their surfaces on various sides; or possibly the practice was meant to improve or test the performance of drill-heads and abrasives.

Specimens in Figure 20(c-d) are also unusual. They are parts of bases of white-banded calcite vessels which retain in the centre of the interior a bulging cone formed by the rotation of a concave drill head. The precise tribological process and constraints responsible for this side-effect of drilling are unknown, but the drill head with a central cavity could not have been harder than the perforated rough-out. Possibly it was used with an abrasive. Figure 20(e) is also anomalous, because the known inventories of banded calcite vessels do not include, as far as we know, vessels with rounded bases. The coarse drilling traces visible on the interior demonstrate that the piece was broken while being manufactured, exactly as Figure 20(k): note how in this case the drill penetrated too deep into the base of a roughly dressed carinated pot. Figure $21(\mathrm{f}, \mathrm{j})$ (the first, a coarse bowl in a porous travertine; the second a thick, possibly ovoid vessel) share a defective centring between the drill and the drilled piece; Figure 20 is part of another sub-cylindrical pot in white banded calcite which shattered in the same operation, retaining coarse inner drill marks.

Figure 20(g,h) are made of a yellowish, harder metamorphosed fibrous quartzite, rather than of calcite; $^{48}$ and their form does not match with known finished products. Figure $20(\mathrm{~g})$, in particular, shows
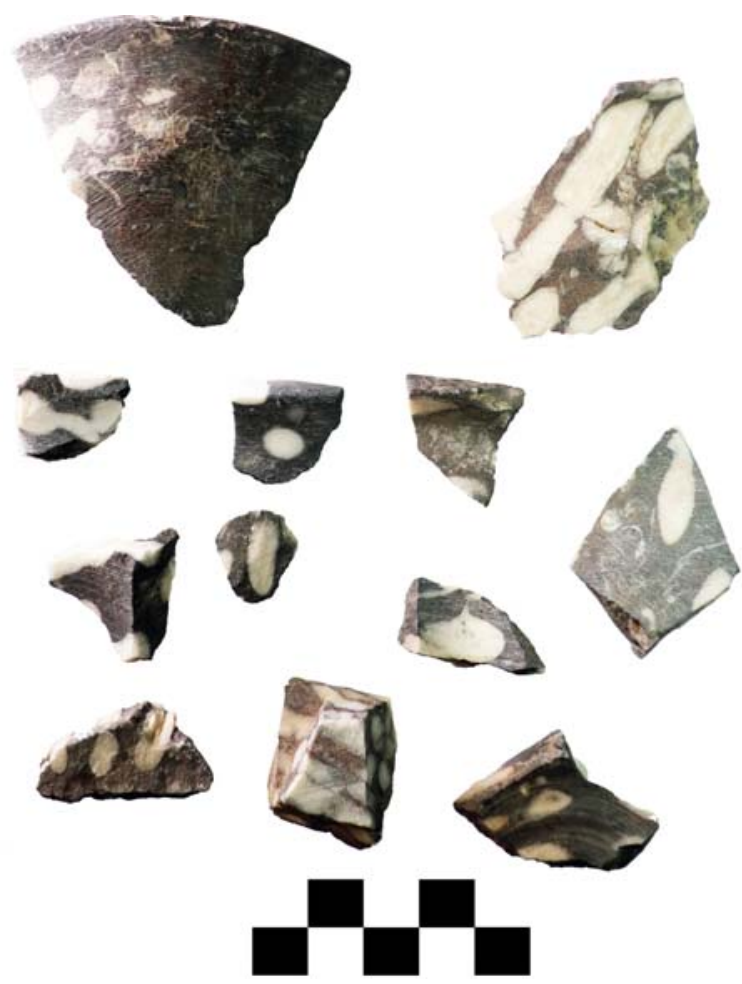

Figure 21. Hajjiabad-Varamin, western slopes of the Main Mound, craft area. Pieces of vessels apparently made in the same workshops with Waagenophyllum coral limestones, found on the surface of the stone-working area.

a continuous chipping along the edge, as if for resharpening it. One wonders whether this piece, and possibly Figure 20(h) were tools - a king of rotating gouge? - rather than products, and similar hard concave disks could have been responsible for the formation, inside the vessels, of the bulging cones of Figure 20(c,d). However, at present it is quite hard to imagine how a similar concave drill-head could have been used for rotational abrasion. ${ }^{49}$

The fragments of vases locally made with Waagenophyllum coral limestone - another distinctive article of trade with Mesopotamia, particularly in the late 3rd millennium $\mathrm{BC}$, also had similar forms (Figure 21). After Shahdad, ${ }^{50}$ where waste rather suggests the manufacture of beads, HajjiabadVaramin is the second early Bronze Age centre certainly involved in the transformation and presumably in the trade of this attractive and uncommon material.

\footnotetext{
${ }^{46}$ Casanova, La Vaisselle d'Albatre de Mésopotamie, d'Iran et d'Asie Centrale, Fig. 5.

${ }^{47}$ Hakemi, Shahdad, 616, for example Fl. 5.

${ }^{48}$ But they have not yet been tested.

${ }^{49}$ Apparently, this possible tool is very similar to that published by Pfälzner and Soleimani, "The ICAR-University of Tübingen South-of-Jiroft Archaeological Survey," fig. 27, upper right.

${ }^{50}$ Ongoing research by the authors and Gianni Marchesi.
} 


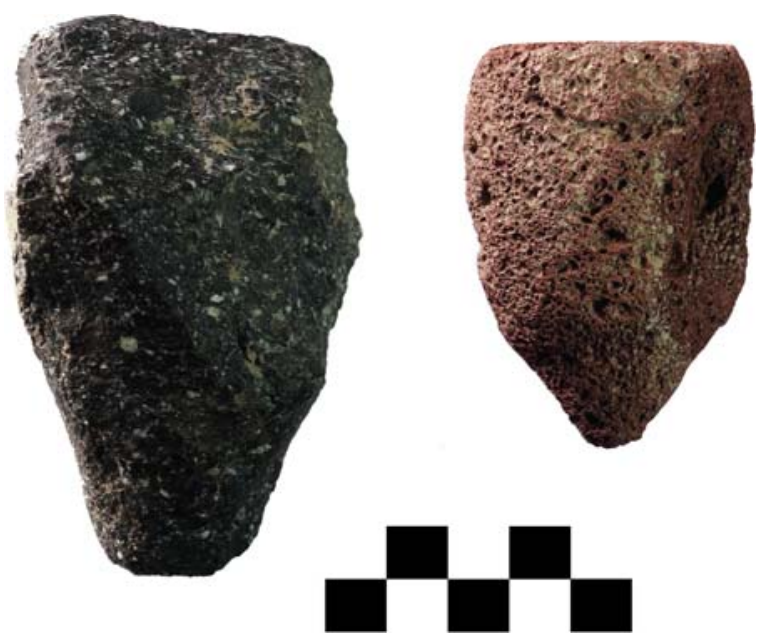

Figure 22. Hajjiabad-Varamin, western slopes of the Main Mound, craft area. (a) heavy polyhedral drill-head in dark reddish-black porphiry; (b) lighter cylindrical drill-head in red vacuolar lava.

\subsection{Drill Heads for Crafting Stone Vessels}

Searching carefully for days among the abundant stone fragments and thousands of pebbles which cover the craft area east of the main mound, we eventually came to recognise a dozen of thick stone points, which, with variable degrees of confidence, were identified as rotating drill heads used for perforating the banded calcite or limestone vessels. Such points, or better drill-heads, may be recognised after the coarse-flaked part, possibly meant to be hafted into a wooden support, above which is visible a tapering, rounded cone-like functional end created by friction.

Among the base materials used for these large drills range a dark red to black very hard porphyry (Figure 22 (a)), and a green-to-grey chert (not illustrated here). The first material was shaped through a bi-facial flaking process from sturdy and thick flakes; with the second, craftsmen prepared preforms similar to cores for flakes and blades, and probably re-sharpened their active end by pecking the surface with bronze tools. Abundant chert flakes and elongated cores found in Trench VI might be related to the fabrication of similar tools. A third, different type of drill point was made of dark red lava (Figure 22(b)). It is endowed with a lateral cylindrical socket, probably used to fix it with a plug to a rotating wooden shaft.

Even though the function of this class of tools, given also the context, is identified beyond doubts, the variety of materials, forms and wear patterns is intriguing and hints to unknown technical adaptations. We are probably dealing with a quite varied and specialised drilling technology, adapted to various steps and materials of

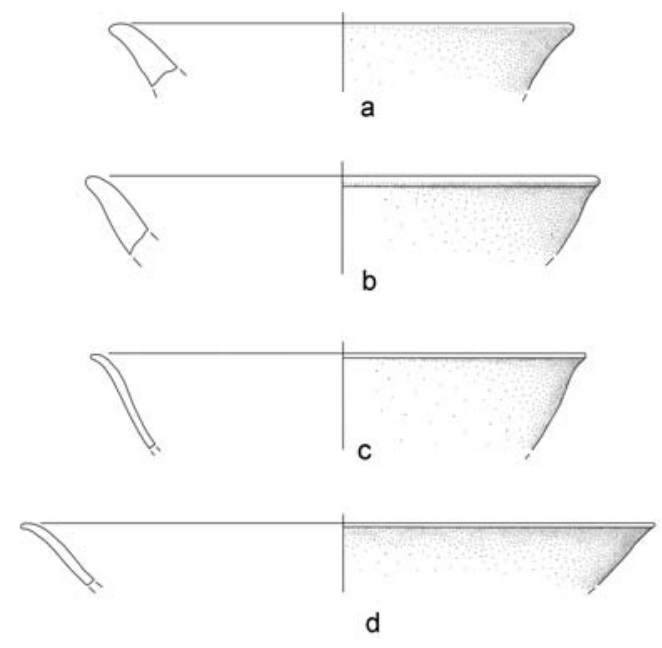

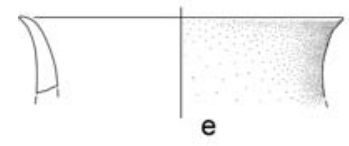


Figure 23. Hajjiabad-Varamin, western slopes of the Main Mound, craft area. Fragments of plain chlorite vessels found on surface.

the perforation process, which will require an in-depth study in a future occasion.

\subsection{Thin Walled, Undecorated Vessels in Chlorite (Bell Bowls and Other Forms)}

In an area of no more than $10 \times 10 \mathrm{~m}$, included in the previously described stone-wo

rking area, there was a concentration of sherds of fine, plain chlorite vessels (Figures 23 and 24). Whether this cluster was formed as a stratified deposit, or dumped in a single event, is impossible to say from surface evidence alone.

If these fragments were actually due to defective manufacturing, these stone vases may have been damaged and broken in the last stages of surface finishing, as also suggested by the absence of indicators 


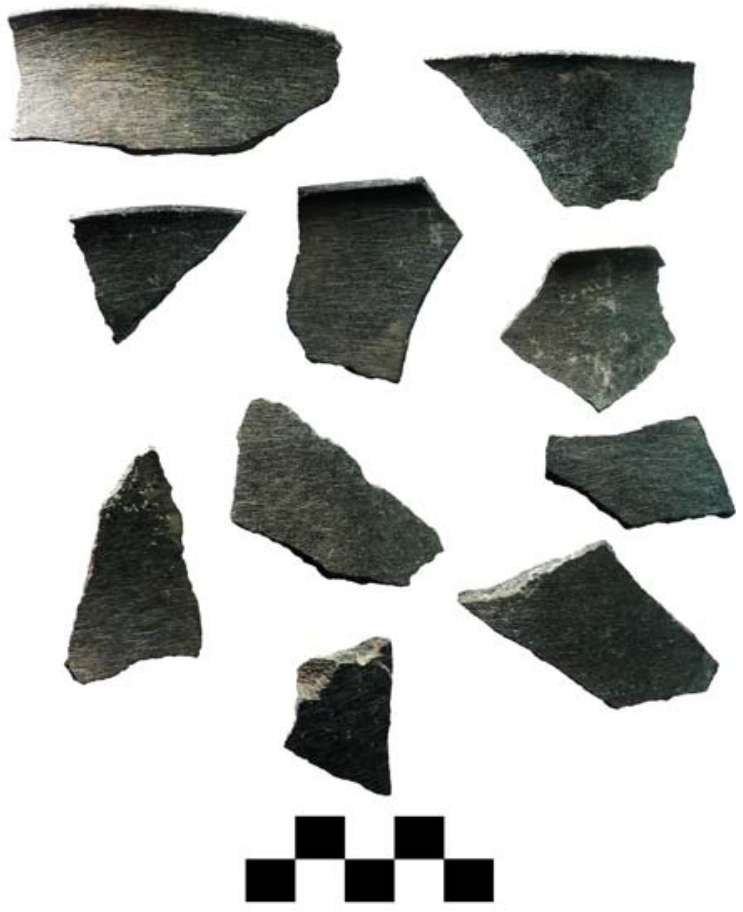

Figure 24. Hajjiabad-Varamin, western slopes of the Main Mound, craft area. Fragments of plain chlorite vessels found on surface.

of previous steps, and by the coarse polishing traces visible on the majority of the sherds (Figure 25). The most common forms are open bowls with S-shaped contours, with walls of variable thickness (Figure 23(a-d)). Other forms, although poorly preserved, might have had concave walls or necks (Figure 23(e-h)), or were tiny subglobular or subcylindrical containers, as suggested by their bases $(j-1)$. Pfälzner and Soleimani ${ }^{51}$ report a fragment of a square compartmented box comparable to those found in Shahdad. ${ }^{52}$

Always in Figure 23, specimens (c-1) were made with a dark green to black fine chloritic rock and had exceedingly thin walls (see specimen I, with a wall thickness ranging between 2 and $3 \mathrm{~mm}$, and those in Figure 24). As producing such fine containers required a great skill, the pots had probably a certain value. They would appear hardly movable, because of their fragility, on long distances. However, "bell-shaped bowls with raised base" 53 are recognised as contemporary to part of the carved
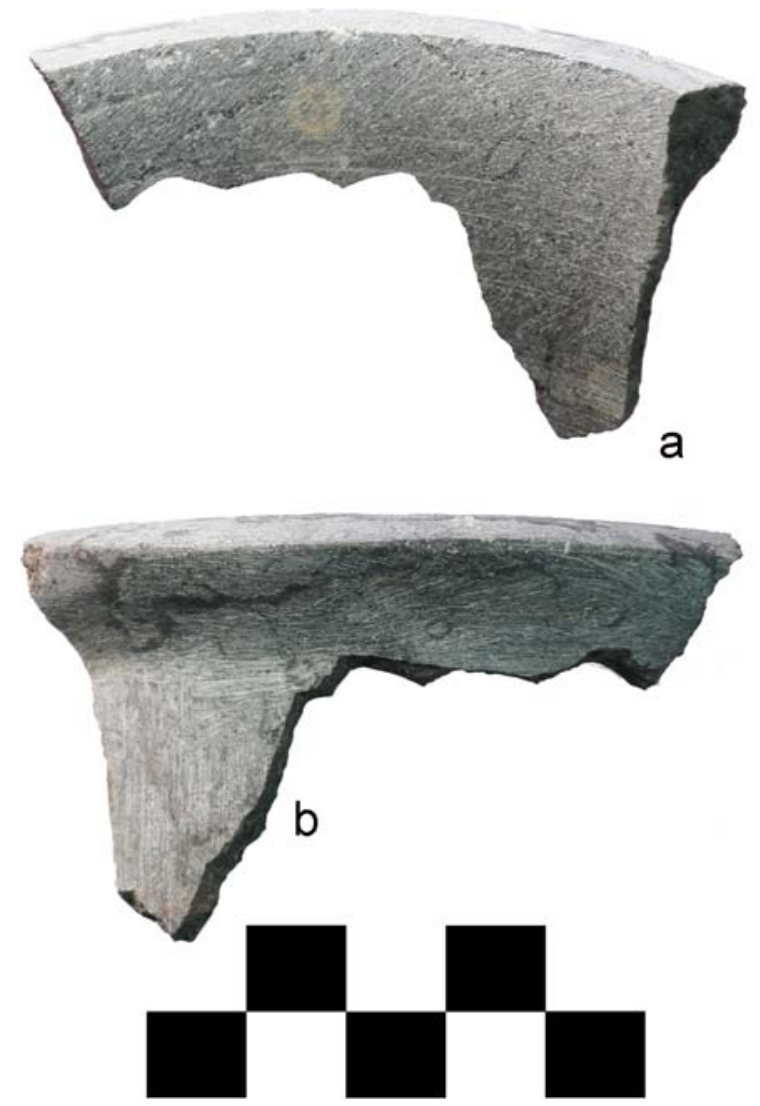

Figure 25. Hajjiabad-Varamin, western slopes of the Main Mound, craft area. Neck fragment, perhaps belonging an unfinished flask-like container, with coarse polishing marks (diagonal inside, orthogonal outside).

chlorite artefacts in the Halil Rud style, for which the generally agreed dating is between 2500 and 2350/2300 BC.

\subsection{Beads in Green and Red-Yellow Banded Calcite}

A substantial group of broken beads of chalcedony, jasper, lapis lazuli and calcite were found in a different spot of the stone working area, in an area of around $10 \times$ $15 \mathrm{~m}$ at the foot of the eastern slope of the main mound (Figure 26). Chalcedony beads were long-barrel or flat ovoid; one was certainly a highly polished "eye bead" in white and grey-brown agate. This group seems to have been locally lost in various episodes and

\footnotetext{
${ }^{51}$ Pfälzner and Soleimani, "The ICAR - University of Tübingen South-of-Jiroft Archaeological Survey," fig. 27, second row, to the right.

${ }^{52}$ Hakemi, Shahdad, 612.

${ }^{53} \mathrm{Kohl}$, "Chlorite and Other Stone Vessels," 285-6. The type is present at Ur in Grave 800 (queen Pu'abi), where seven plain bowls were offered together with other two carved in the Halil Rud elaborated styles (Wooley, Ur Excavations, Vol. 2, 49-51, PI. 245; Kohl and Lyonnet, by "Land and By Sea," 37; Kohl, "Chlorite and Other Stone Vessels and their Exchange"). Hilton, The Stone Vessels, 61, Figs. 69-78, publishes several specimens of this type from Failaka at the mouth of the Persian Gulf, noting " ... morphological similarities with bowls excavated at cemetery sites such as Shahdad, Jiroft, Rufay'a, Ur and Hili North Tomb A ... at Tepe Yahya and the Barbar Temple on Bahrain." Other specimens were found at Tarut (Zarins, Typological Study in Saudi Arabian Archaeology, Pls. 64, 33 and 65, 87). At Shahdad, they were recovered from graves of Cemetery A (Hakemi, Shahdad, 605-7). Others came from the workshop area of at Tepe Yahya, as published in Kohl, "Reflections on the Production of Chlorite." The base fragment in our Figure 22l seems very similar to others from Tarut (Zarins' specimens at Pl. 64, 72 or Pl. 65, 325) and to specimens from Shahdad Cemetery A (Hakemi, Shahdad, 607, Fd. 2 and 4). The attention for the exploitation of the chloritic rocks in the Kerman region, in the meantime, is growing (Emami et al., "New insights into the characterization and provenance of chlorite objects").
} 


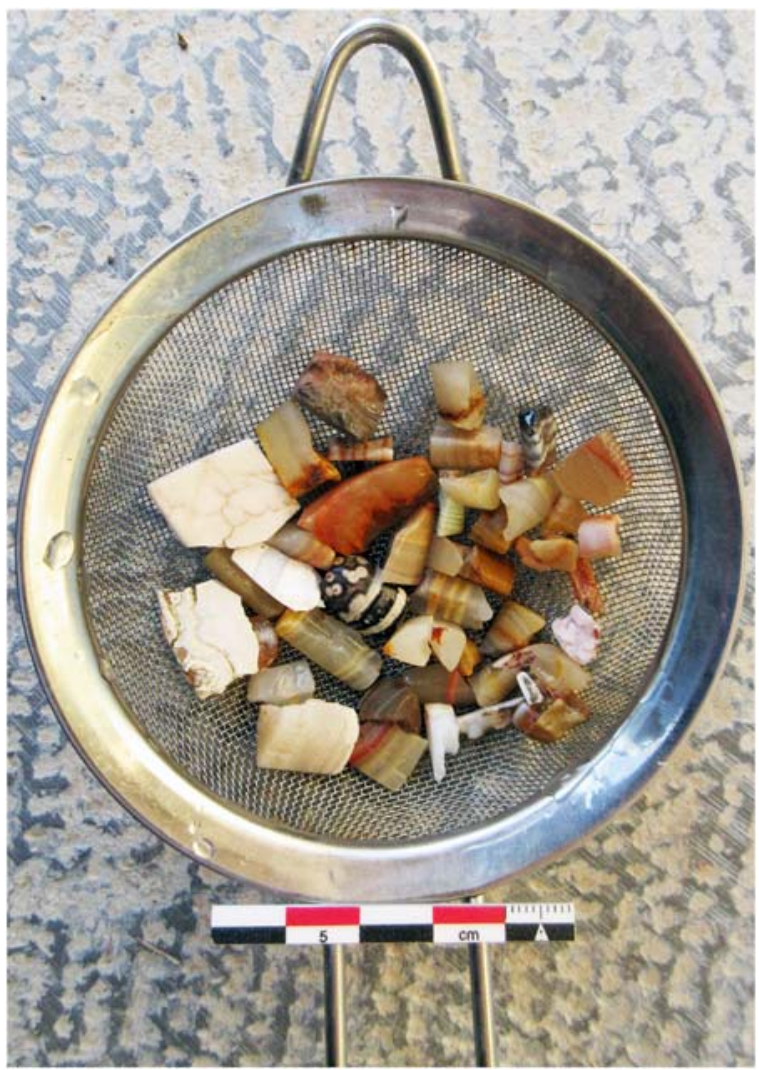

Figure 26. Hajjiabad-Varamin, western slopes of the Main Mound, craft area. Part of the beads found on the surface of the stone-working area.

badly damaged by trampling and other post-depositional processes, as also shown by the corrosion and extensive bleaching of the agate and carnelian bead fragments.

In contrast, many other beads fragments (Figure 27) were made of the same brown and red-yellow banded calcite, and belonged to the same formal type: rectangular in contour, with a triangular section, rounded at the corners. The axes of the drill holes are always orthogonal to the natural bands. The beads measured from about 1.1 to $1.8 \mathrm{~cm}$ in length, while the thickness varied from a minimum of 0.3 to a maximum of $1.1 \mathrm{~cm}$, with average values around $0.5-0.6 \mathrm{~cm}$. At any rate, we have searched in the published beads repertories for other examples of the same bead type (at Shahdad, Shahr-i Sokhta and Tepe Hissar, to quote the most important coeval beads repertories), ${ }^{54}$ and found none. Differently from the stone pots, these beads might have been a locally traded commodity.

All beads were split in two halves while being drilled, at the same step of a quite repetitive and standardised chaîne opératoire. A puzzling aspect is the total absence, in this surface collection, of the chipped stone drill heads which regularly accompanied, in the ancient dumps and surfaces of activity, the damaged beads. ${ }^{55}$ The only (hypothetical) explanation is that such ornaments were perforated with copper drills.

Figure 28 compares SEM images of the holes of two banded calcite split beads ((a) and (b), at left) with the holes of two agate beads of the first group, ((c) and (d), at right). The perforations of Figure 28(a-b) look rather similar to those normally left by a chipped chert drill head, but we cannot exclude the use of a copper point with an abrasive, particularly for the two ringlike expansions visible near the end in b. In contrast, Figure $28(\mathrm{c}-\mathrm{d})$ are clearly what remains of holes made with longer stone cylindrical drill heads like those in use at Shahr-i Sokhta, Mehrgarh and particularly in Indus workshops. ${ }^{56}$ This eventually confirms that this heterogeneous group of badly damaged beads is different and intrusive in the context of the former.

\section{A Hoard of Copper Objects}

The hoard (map in Figure 7(b) and Figures 29 and 30), outcropped on a portion of the flat surface in the southern part of the site, almost free of ceramics or other artefacts. The area had been extensively cut on top and levelled by recent agricultural interventions, and further washed off by rain; it was impossible to ascertain an original context or associations of the buried deposit. All vessels were heavily corroded, cracked and partially broken; pieces of the rims were already detached and scattered nearby the find spot. Discovered in the late afternoon, the hoard was rapidly excavated in conditions of emergency, since we did not want letting it overnight without custody.

The burial event may be reconstructed as follows. Five large copper objects (three spouted pots, an axe and an adze) were kept in a light perishable container. Clear pseudomorphic impressions of woven fibres on rear of the axe indicate a sack. This latter and its heavy content were placed in a round pit, about 50 $55 \mathrm{~cm}$ wide; the original depth from surface, of course, is unknown. In the process, the two heavier items (the adze and the axe) shifted to the bottom, below the three globular vessels. These latter rested with the spouts converging toward the centre, the position of minimum resistance to the tension of the sack's cloth.

\footnotetext{
${ }^{54}$ Bead repertories in Hakemi, Shahdad; Piperno and Salvatori, The Shahr-i Sokhta Graveyard; Schmidt, Excavations at Tepe Hissar.

${ }^{55} \mathrm{Cf}$., for example, Rafifar et al., "Janbe hayy as fannavary mathekhary dar Konar Sandal Junuby."

${ }^{56}$ Among many others, Piperno, "Micro-Drilling at Shahr-i Sokhta"; Kenoyer and Vidale, "A New Look into the Stone Drills of the Indus Valley Tradition"; Vidale et al., "Early Evidence of Bead-Making at Mehrgarh."
} 

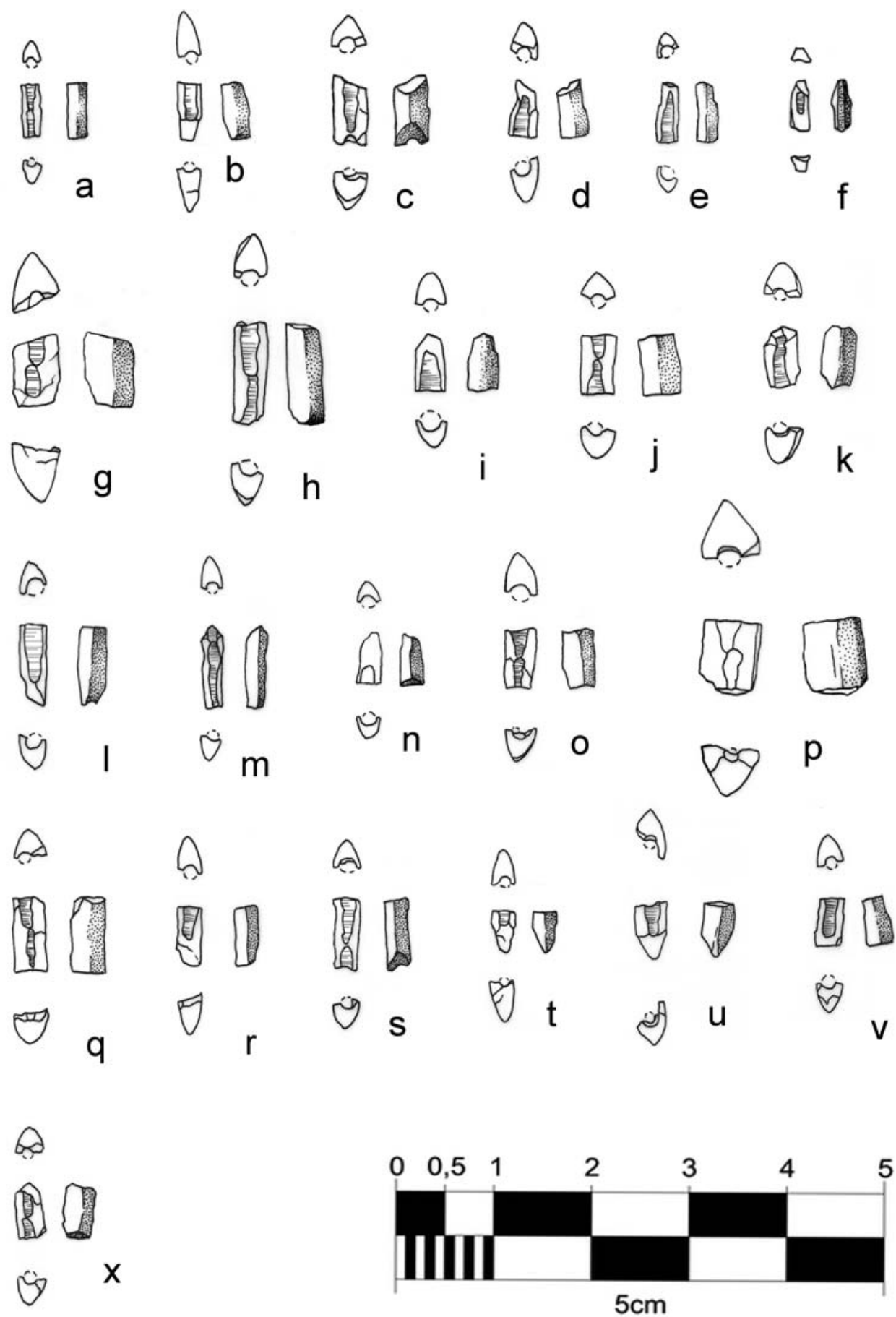

Figure 27. Hajjiabad-Varamin, western slopes of the Main Mound, craft area. (a-x): rectangular beads in green and red-yellow banded calcite, with a sub-triangular section, found on the surface of the stone-working area. This image shows about half of the collected beads. All belong to the same type and were split in the same drilling stage, indirectly witnessing through the error the noticeable standardisation of the manufacturing sequence.

The filling of the round pit was free from archaeological inclusions, and no remains of archaeological features or layers survived in the immediate surroundings. The hoard seems to have been buried in a clean, perhaps open area; not much was left by the intensive erosion of the centre of the site. In such conditions the other contingencies and reasons of hoarding, and of the ultimate abandonment or loss of these valuable finds, will remain undisclosed. ${ }^{57}$

\footnotetext{
${ }^{57}$ All the fragments were first cleaned with an ethanol-water mixture (70:30) using brushes. Then a limited soft cleaning was performed with a micro-drill. Once removed the thickest soil deposits, all fragments were dehydrated with acetone. The cleaning was partial, and the objects not coated, so that in future it will
} 


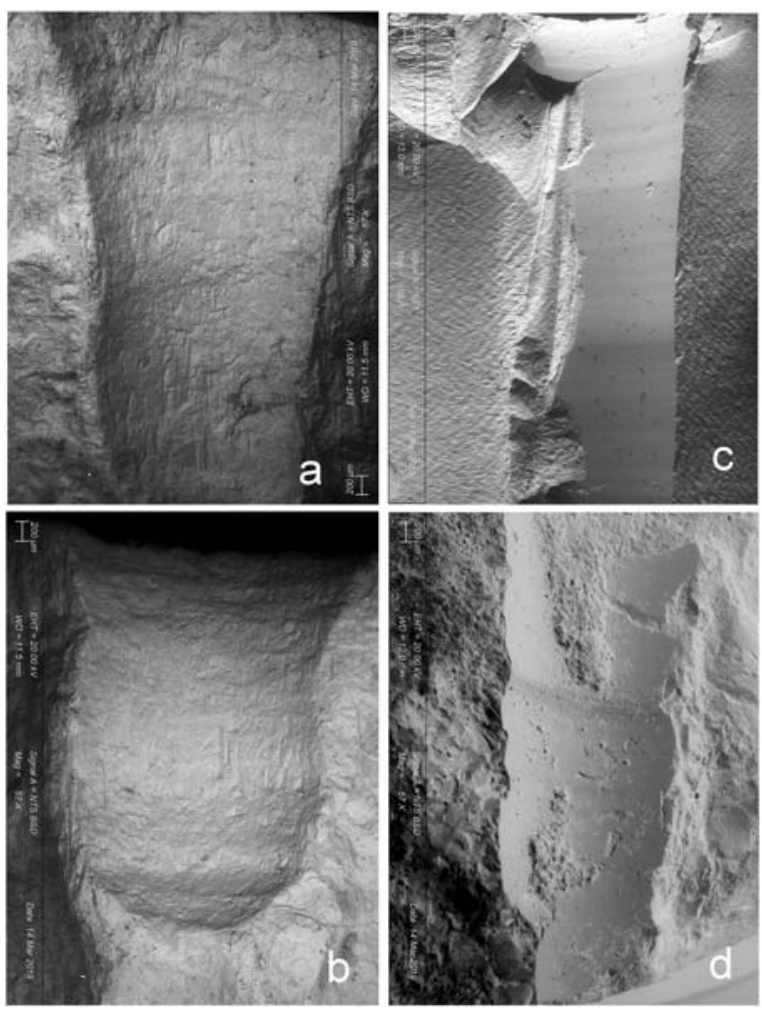

Figure 28. Hajjiabad-Varamin, western slopes of the Main Mound, craft area. Rectangular beads in green and red-yellow banded calcite: ESEM images of the holes of two banded calcite split beads ((a) and (b), at left) and of the holes of two agate beads ((c) and (d), at right) found on the surface of the stoneworking area. (c) and (d) were perforated with cylindrical stone drill heads, with Indus-related techniques.

Up to now, the three vessels of the hoard ${ }^{58}$ are the only specimens of this kind found in a regular excavation in the Halil Rud valley, in the course of which similar objects were previously attested as looted finds. ${ }^{59}$ Table 2 presents measurements and descriptions for Vessels 1, 2 and 3. Then follows a description of Axe 1 and Adze 1.

Axe 1: length $13.5 \mathrm{~cm}$, maximum width of the blade $9.5 \mathrm{~cm}$; maximum width of the shaft $3.4 \mathrm{~cm}$. The blade of the axe is curved, with a thick blunt edge that suggests it was never used. The rear of the shaft is gently curved, with diverging ends.

Adze 1: length $14 \mathrm{~cm}$, maximum width of the blade $8.8 \mathrm{~cm}$; maximum width of the shaft $3.5 \mathrm{~cm}$. As observed for the axe, the blade is apparently intact, as it was never used, an impression supported by the blunt edge. This latter has a marginal carination on the lower side. The lower sides of the adze join the shaft with two convergent ridges in relief. ${ }^{60}$

\section{Conclusions}

Although advanced erosion, large-scale earthworks and lootings determine a generally fragmented and discontinuous perception of the site's history, the survey is providing new data on the local processes of early urbanisation, the evolution of the Halil Rud civilisation and its involvement in long-distance trade. The local diachronic settlement periods from the late 5th to the 3rd millennium BC are now preliminarily labelled, in sequence, Gaz Saleh, Mahtoutabad I/Early Aliabad, Aliabad, Varamin and Konar Sandal South periods. ${ }^{61}$

Site formation processes, as well as old and recent disturbances were carefully evaluated during the survey,

be possible to extend the conservation treatment. The fragments were protected with an acrylic resin; after which, we temporarily reconstructed the forms with adhesive tape, for finding the position of the small fragments and the best order to follow to glue them with an epoxy resin. The axe and the adze were softly cleaned, removing most of the soil deposits, with solvents applied by brush, and were not coated. Since the corroded surface of the adze was extremely fragile and detached from the metal below, it was consolidated with an acrylic resin applied in growing percentages. The entire hoard is currently on display in a showcase of the Archaeological Museum of Jiroft.

${ }^{58}$ In general, see Bellelli, Vasi iranici in metallo dell'Età del Bronzo, 119-21 and Tables 23 and 28. While such spouted vessels might remind more ancient example of the late 4th or early 3rd millennium BC, for example at Susa in Grave $n^{\circ} 576$ (Carter, Excavations in Ville Royale 1 at Susa, fig. 6), in the layer 18/17 of the Ville Royale I trench in Susa, the best comparisons point to the middle of the 3rd millennium BC. Several spouted copper vessels were found in Shahdad Cemetery A, see Hakemi, Shahdad, 630 and 631). In the illustrated group, Gf. 5 shows a hemispherical bulging expansion below the spout, which might recall the double festoon or circle incised as flat motifs in the same position in our Vessels 1 and 2. A fragmentary pot of the same form was found in the looted grave $\mathrm{n}^{\circ} 114$ in Spidej, in the Jazmurian basin (M. Heydari, personal communication). See also a vessel from Bactria (Pottier, Matériel funéraire, $\mathrm{n}^{\circ} 243$ and Amiet, "Bactriane Protohistorique," 196 and fig. 161). Other examples were found in Susa (de Mecquenem, Offrandes de fondation du temple de Chouchinak, fig. 21, $\mathrm{n}^{\circ} 3$ in the Vase à la cachette; 216, fig. 60, $\mathrm{n}^{\circ} 19$ and 20; Le Breton, "The early periods at Susa," fig. 41, $\mathrm{n}^{\circ} 5,7$ and 8 and Tallon, Métallurgie susienne I, 216-17) and attributed by Le Breton to Susa D. Three vessels, similar but more cylindrical, found in stone-built graves in Gilvaran, just west of Khorammabad in Luristan (Herzfeld, Berichtüber archäologische Beobachtunge-nimsüdlichen Kurdistan und in Luristan, 70 and 71 , Tables VI and VII; Parviz and Khadish, "The Elite Early Bronze Age Graves," 109, $\left.\mathrm{n}^{\circ} 25\right)$, all with incisions. One, notably, bears a circle under the spout reminding the hemispherical bulging expansion below the spout in a copper pot from Shahdad, and the flat decoration in Vessels 1 and 2 of the hoard. Cylindrical is also a vessel found in Girsu/Tello (de Sarzec, Découverte en Chaldée, Tome I, 410).

${ }^{59}$ Madjidzadeh, Jiroft: The Earliest Oriental Civilization, 157, upper left, and unpublished material from the Archaeological Museum of Jiroft.

${ }^{60}$ Comparisons for axe 1 are found at Shahdad in Cemetery A (Hakemi, Shahdad, 636, Gp. 3 and Gp. 4), more precisely in Cemeteries B (ibid. 693, Qa. 3) and C (ibid. 698, Ta. 3). However, in all these specimens the blade is less expanded. A mold possibly used for producing an object of the same kind was found in the so-called Site D or "metallurgical workshops," together with the cylindrical plugs needed for casting the hole of the shaft (ibid. 707, Wa. 1). Adze 1 is rather similar to a tool from the same Cemetery (ibid. 638, Gp. 12), but for the marginal ridges on the lower surface, absent in the Shahdad specimen. Madjidzadeh, in Jiroft: The Earliest Oriental Civilization, 158 also reported a similar adze.

${ }^{61}$ The new evidence will also be used as a further reference for the different surveys led in Jiroft up to now. It also improves the available keys to understand the unfortunately more than abundant antiquités orphelines confiscated by Iranian authorities in the last years after the massive lootings, still waiting to be studied in the store rooms of the Archaeological Museum of Jiroft and the Jiroft Cultural Heritage base. This is one of the goals we will try to achieve in the next campaigns. 


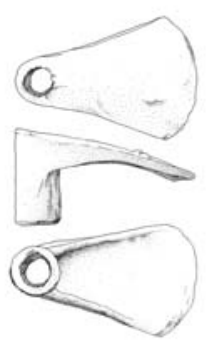

adze 1

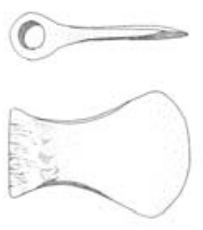

axe 1

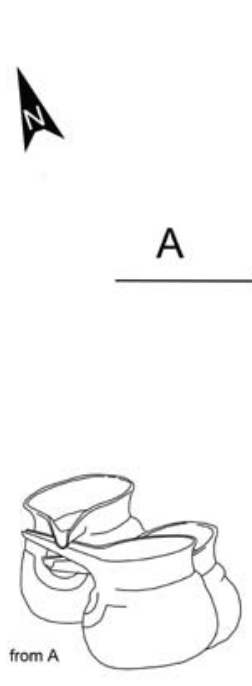

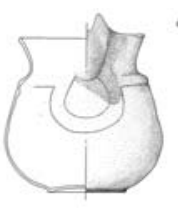

vessel 1
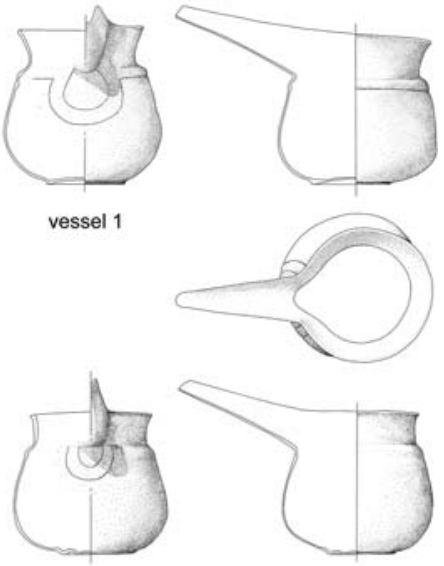

vessel 2
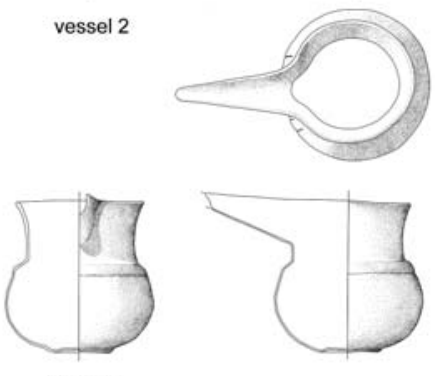

vessel 3
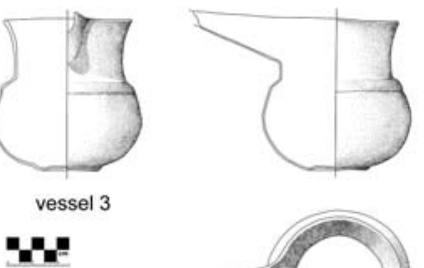

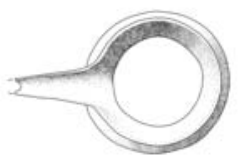

Figure 29. The Hajjiabad-Varamin copper hoard: above, at right, the three Vessels, the axe and the adze from different viepoints. Below, left, a plan of the find, accompanied by two lateral views. The round pit containing the hoard, only partially visible during the rescue, is shown as a thick dashed line.

and additional ground testing appear mandatory before coming to general conclusions. Our data make clear that the outer limits of the overall archaeological evidences cannot be taken as the actual maximum extension of the settlement in a given moment. Although the site was described as "clearly urban in scale", ${ }^{62}$ and possibly linked in an unknown way to the nearby large site of Marjan-Varamin, the survey generates new questions.

The Chalcolithic and early Bronze Age settlement grew in form of overlapping patchworks of discrete occupations, much less extensive, even if taken together, than the $115-116$ ha previously measured, ${ }^{63}$ and shifting in time with different functions for almost two millennia, generally moving from south northwards. The occupation of the late 4 th-early 3 rd millennium BC or Varamin period, as inferred by ceramics recently scattered on surface after looting of a large local cemetery, needs to be clarified by further digs and, at present, cannot be considered in the flattening terms of an uniform, incremental urban expansion.

For the second half of the 3rd millennium BC we record a second damaged graveyard, but the

\footnotetext{
${ }^{62}$ Pfälzner et al., "The ICAR - University of Tübingen South-of-Jiroft Archaeological Survey," 129.

${ }^{63} \mathrm{Ibid}$., at 127, Hajjiabad-Varamin is said to extend for $116 \mathrm{ha}$, and Marjan-Varamin for 106 ha. The authors here also state that the extension of the two Varamin sites increased from what they call Late Chalcolithic 2 (Aliabad period) to the first half of the 3rd millennium BC, but later, at p. 129, the size of Marjan-Varamin in this last period is reported as 75 ha.
} 


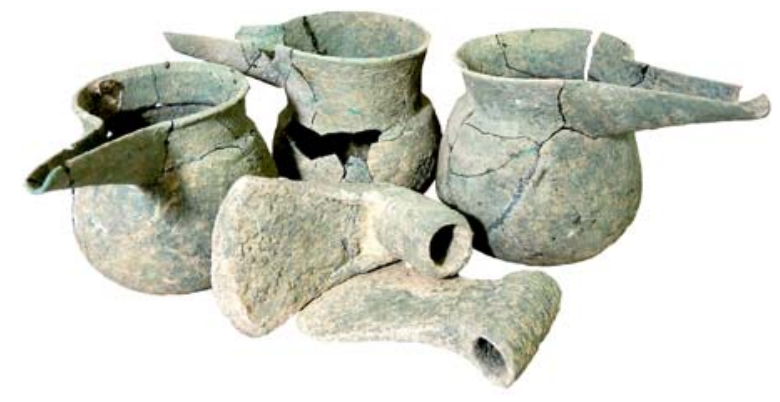

Figure 30. The Hajjiabad-Varamin copper hoard, at the end of restoration.

Table 2. Descriptions of the three vessels of the HajjiabadVaramin copper hoard (measurements in $\mathrm{cm}$ ).

\begin{tabular}{ccccccc}
\hline & Height & $\begin{array}{c}\text { Mouth } \\
\text { diam }\end{array}$ & $\begin{array}{c}\text { Max } \\
\text { diam }\end{array}$ & $\begin{array}{c}\text { Neck } \\
\text { height }\end{array}$ & $\begin{array}{c}\text { Spout } \\
\text { length }\end{array}$ & Description \\
\hline $\begin{array}{c}\text { Vessel } \\
1\end{array}$ & 12.6 & 10.8 & 11.6 & 3.0 & 10 & $\begin{array}{c}\text { Slightly everted } \\
\text { mouth. Double }\end{array}$
\end{tabular}

festoon below the spout

(diam $7 \mathrm{~cm}$ ).

Two embossed

circles on the

outer bottom

(diam $5 \mathrm{~cm}$ ).

More deformed

from corrosion

and pressure

than the others

$\begin{array}{lllllll}\text { Vessel } & 11.5 & 9.7 & 12 & 2.5 & 9.2 & \text { Slightly everted }\end{array}$

2 mouth,

rounded rim.

Double festoon

below the

spout (diam

$5 \mathrm{~cm})$. Two

embossed

circles on the

outer bottom

(diam $5 \mathrm{~cm}$ )

$\begin{array}{lllllll}\text { Vessel } & 12.0 & 10.0 & 12.0 & 4.7 & \text { ca. 9- } & \text { Slightly everted }\end{array}$

3

10

mouth.

Continuous

horizontal line

below the

shoulder. Two embossed

circles on the

outer bottom

(diam $5 \mathrm{~cm}$ )

extension of the contemporary settlement remains hypothetical. The mounds with early historic materials on surface are totally unexplored, and the Islamic city (now almost completely effaced by erosion) was certainly involved in a range of skilled craft activities (ceramics, metalworking, glassmaking, jasper beads production) which deserve future dedicated investigations.

Focusing on the later 3rd millennium BC or Konar Sandal South period, the large craft area in which beads and vessels of banded calcite, fossiliferous limestone and chlorite were produced, ${ }^{64}$ has important implications for the long-distance links and trade in luxury commodities from the Iranian Plateau and the west between the twenty-fourth and twenty-third centuries BC (dates suggested by cross-site comparisons). The local production of small calcite and limestone carinated pots, possibly used for cosmetics or other valuable organic substances, and of a type of plain, bell-shaped fine chlorite bowls, reveals that Hajjiabad-Varamin was a pulsating ring of a long trade-exchange chain that directly linked its craft communities to sites like Shahdad and Tepe Yahya, and southwards to Bahrein, Tarut and Failaka, eventually landing to the docks of Ur. The impact of the production and trade of bellshaped bowls and other finely plain crafted containers in the same stone, so far, was somehow neglected (in contrast, as far as we presently know, green-banded calcite beads were locally wanted). Finally, the absence at Hajjiabad-Varamin of traces left by the production of the more famous figurated chlorite artefacts of the same period suggests that these latter and plain belllike bowls were two differently specialised spheres of production.

The evidence gives further material ground to the idea that the Halil Rud cities in mid-3rd millennium BC played a crucial role in the trade of valuable materials - in first place calcite vessels - from the inner Iranian Plateau westwards, through the Persian Gulf. $^{65}$ The copper hoard belongs to the same period; on the whole, the wide circulation of such luxury commodities and their aesthetics may have been at the roots of the keen interest of the Akkadian courts for the apparent wealth of their eastern neighbours.

\section{Acknowledgements}

The referees' comments greatly improved a first version of this article. We are thankful to ICAR; this work has been supported by the Center for International Scientific Studies and Collaboration (CISSC), Ministry of Science Research and Technology, Islamic Republic of Iran, University of Jiroft, by ISMEO (Rome) and the Dept. of Cultural Heritage, University of Padova (Italy). Giancarlo Sidoti, ISCR, Rome, generously helped us for the analysis of tiny fragments of the

\footnotetext{
${ }^{64}$ The two craft activities are not necessarily contemporaneous. The calcite workshop area has on surface small potsherds (of the size generally encountered on Bronze Age dumps) of both the Varamin and Konar Sandal South periods. If the bowls of calcite and chlorite are reasonably datable after stylistic comparisons, little can be said for the rectangular beads with triangular sections.

${ }^{65}$ See Steinkeller, "Trade Routes and Commercial Networks," 413: note, however, that the author hypothesizes the flourishing of the trade through Marhaši at the end of the 3rd millennium BC, for which, at Konar Sandal, still we have no factual evidence.
} 
calcite beads. We are also deeply indebted with Sergio Gnutti and Antonella Zanini (EURAL SPA) for their continuous support. We would like to thank the excellent students of the University of Jiroft, Shahrzad Hashemipour, Mahdi Assad, Amin Mahani, Soudeh Lovari, Matin Karimi and Nasim Mashayekhi for their help in the field.

\section{Disclosure Statement}

No potential conflict of interest was reported by the author(s).

\section{Funding}

This work has been supported by the Center for International Scientific Studies and Collaboration (CISSC), Ministry of Science Research and Technology, Islamic Republic of Iran, University of Jiroft, by ISMEO (Rome) and the Dept. of Cultural Heritage, University of Padova (Italy).

\section{ORCID}

Nasir Eskandari (D) http://orcid.org/0000-0001-8461-9000

\section{Bibliography}

Amiet, P. "Bactriane Protohistorique." Syria 54 (1977): 89124.

Amiet, P. L'âge des échanges inter-iraniens, 3500-1700 avant JC. Notes et documents des Musées de France 11. Paris: Editions de la réunion des musées nationaux, 1986.

Beck, H. C. "Classification and Nomenclature of Beads and Pendants." Archaeologia 77 (1928): 1-76.

Bellelli, G. M. Vasi iranici in metallo dell'Età del Bronzo. Prähistorische Bronzefunde, abteilung II, band 17 . Stuttgart: Franz Steiner, 2002.

Benoit, A. "Vase à la cachette." In Art of the First Cities, edited by J. Aruz and R. Wallenfels, 302-305. New York: Metropolitan Museum of Art and Yale University Press, 2003.

Boccuti, S., A. Squitieri, G. Angelini, A. Lazzari, E. Di Luzio, and M. Albano. "Preliminary Surface Analyses by ESEM-EDS of Calcite Bowls from Shahr-i Sokhta (Sistan, Iran, ca. 3200-1800 BCE): Results and Possible Interpretations." Journal of Archaeological Science 61 (2015): 244-259.

Caldwell, J. R. Excavations at Tal-i Iblis. Preliminary Reports, No. 9. Springfield: Illinois State Museum, 1967.

Carter, E. "Excavations in Ville Royale 1 at Susa: the Third Millennium BC Occupation.” Cahiers de la Délégation Française en Iran 11 (1980): 11-134.

Casanova, M. La Vaisselle d'Albatre de Mésopotamie, d'Iran et d'Asie Centrale aux IIIe et IIe Millénaires Avant J.-C. Mémoires de la Mission Archéologique Centre de Recherches Française en Asie Centrale d'Archéologie Orientale, Tome IV. Paris: Université de Paris I, Éditions Recherche sur les Civilisations, 1991.

Ciarla, R. "The Manufacture of Alabaster Vessels at Shahr-i Sokhta and Mundigak in 3rd Millennium BC: A Problem of Cultural Identity." In Iranica, edited by G. Gnoli and
A. V. Rossi, 319-335. Naples: Istituto Universitario Orientale, 1979.

Ciarla, R. "A Preliminary Analysis of the Manufacture of Alabaster Vessels at Shahr-i Sokhta and Mundigak in the 3rd Millennium BC." In South Asian Archaeology 1979, edited by H. Haertel, 45-63. Berlin: Dietrich Reimer, 1981.

Ciarla, R. "New Material in the Study of the Manufacture of Stone Vases at Shahr-i Sokhta." East and West 35 (1985): 418-425.

Ciarla, R. "Fragments of Stone Vases as a Base Material. Two Case Studies: Failaka and Shahr-i Sokhta." In South Asian Archaeology 1987, edited by M. Taddei, 475-491, Serie Orientale LXVI, 1. Roma: IsMEO, 1990.

De Cardi, B. Excavations at Bampur, a Third Millennium Settlement in Persian Baluchistan, 1966. New York: Anthropological Papers of the American Museum of Natural History 51, $\mathrm{n}^{\circ} 3,1970$.

Desset, F., G. Marchesi, M. Vidale, and J. Pignatti. "A Sculpted Dish from Tello Made of a Rare Stone (Louvre-AO 153)." Journal of Near Eastern Studies 75, no. 1 (2016): 71-84.

Desset, F., M. Vidale, and N. Alidadi Soleimani. "Mahtoutabad III (Province of Kerman, Iran): An 'UrukRelated' Material Assemblage in Eastern Iran." Iran 51 (2013): 17-54.

Desset, F., M. Vidale, N. Alidadi Soleimani, E. Battistella, and A. Daneshi. "A Grave of the Halil Rud Valley (Jiroft, Iran, ca. 2400-2200 BC): Stratigraphy, Taphonomy, Funerary Practice." Iranica Antiqua 52 (2017): 25-60.

Emami, M., M. Razanib, N. Alidadi Soleimani, and Y. Madjidzadeh. "New Insights into the Characterization and Provenance of Chlorite Objects from the Jiroft Civilization in Iran.” Journal of Archaeological Science: Reports 16 (2017): 194-204.

Eskandari, N. "Excavations at the Prehistoric Sites of Tepe Dehno and Tepe East Dehno, Shahdad, South-Eastern Iran." Iranian Journal of Archaeological Studies 7, no. 1 (2017): 16-33.

Eskandari, N. "A Reappraisal of the Chronology of the Chalcolithic Period in SE Iran: Absolute and Relative Chronology of Tepe Dehno and Tepe East Dehno, Shahdad." Journal of Research on Archaeometry 4 (2018): 23-35.

Eskandari, N., H. Molasalehi, M. Shafiee, and A. Abedi. "Excavations at the Bronze Age Pastoral Site of Hanzaf, SE Iran: Strategy of Pastoralism in the Halil Rud Basin Based on the Archaeological and Ethno-Archaeological Evidence." Mediterranean Archaeology \& Archaeometry 19, no. 1 (2019): 143-156.

Eskandari, N., F. Desset, M. Hessari, M. Shahsavari, M. Shafiee, and M. Vidale. "A Late 4th to Early 3rd Millennium BC Grave in Hajjiabad-Varamin (Jiroft, South-Eastern Iran): Defining a New Period of the Halil Rud Valley Prehistoric Sequence." Iranica Antiqua 55 (2020): 1-48.

Eskandari, N., P. Pfälzner, and N. Alidadi Soleimani. “The formation of the Early Bronze Age Jiroft Culture, Halilrud Basin, SE Iran: Excavations at Varamin Jiroft 2017.” Forthcoming-a.

Franke, U., and E. Cortesi. Lost and Found. Prehistoric Pottery Treasures from Baluchistan. Berlin: Pergamon Museum, 2015. 
Glob, M. P. V. “Alabaster Vases from the Barbar Temples. The Danish Archaeological Bahrein-Expedition's Excavation Fifth Campaign.” KUML 8, no. 8 (1958): 38-145.

Catalogue de l'exposition Lut-Xabis (Shahdad). "Premier symposium annuel de la recherche archéologique en Iran.” festival de la culture, Téhéran, 1972.

Hakemi, A. Shahdad. Archaeological Excavations of a Bronze Age Center in Iran. Rome: IsIAO, 1997.

Heidary, M., F. Desset, and M. Vidale. "A Late 4th-Early 3rd Millennium BC Grave at Spidej (Eastern Jazmurian, Iranian Baluchistan).” Iranica Antiqua 54 (2019): 17-58.

Heydari, M., H. Fazeli Nashli, E. Cortesi, and M. Vidale. “A Surface Collection at Chegerdak, a Bronze Age Centre in the Jazmurian Basin (South-Eastern Iran).” Paléorient 41, no. 2 (2015): 133-155.

Herzfeld, E. "Berichtüber archäologische Beobachtungenimsüdlichen Kurdistan und in Luristan.” Archäologische Mitteilugen aus Iran 1 (1929/30): 65-75.

Hilton, A. The Stone Vessels: Failaka / Dilmun: the Second Millennium Settlements. Aarhus: Universitetsforlag Aarhus, 2014.

Kavosh, H. A., M. Vidale M, and H. Fazeli. Tappeh Graziani, Sistan, Iran: Stratigraphy, Formation Processes and Chronology of a Suburban Site of Shahr-i Sokhta. Prehistoric Sistan 2. Padova: Antilia, 2019.

Kenoyer, J. M., and M. Vidale. "A New Look into the Stone Drills of the Indus Valley Tradition." In Materials Issues in Art and Archaeology III. Materials Research Society Symposium Proceedings 267, edited by P. B. Vandiver, J. R. Druzik, G. S. Wheeler, and I. C. Freestone, 495-518. Pittsburgh: Material Research Society, 1992.

Kohl, P. "Reflections on the Production of Chlorite at Tepe Yahya." In Excavations at Tepe Yahya, Iran, 1967-1975, edited by C. C. Lamberg-Karlovsky and D. T. Potts, 209230. American School of Prehistoric Research, Bulletin 27. Cambridge: Peabody Museum of Archaeology and Ethnology, Harvard University, 2001.

Kohl, P. "Chlorite and Other Stone Vessels and Their Exchange on the Iranian Plateau and Beyond." Persiens Antike Pracht: Katalog der Ausstellung des Deutschen Bergbau-Museum Bochum 1 (2004): 282-289.

Kohl, P. L., and B. Lyonnet. "By Land and By Sea: The Circulation of Materials and Peoples, ca. 3500-1800 B.C." In Intercultural Relations Between South and Southwest Asia. Studies in Commemoration of E.C.L. During Caspers (1934-1996), edited by E. Olijdam and R. H. Spoor, 2942. Oxford: BAR International Series 1826, 2008.

Lamberg-Karlovsky, C. C., and T. W. Beale. Excavations at Tepe Yahya, Iran, 1967-1975: The Early Periods. Bulletin of the American School of Prehistoric Research. Cambridge, MA: Peabody Museum of Archaeology and Ethnology, Harvard University, 1986.

Lamberg-Karlovsky, C. C., and D. T. Potts. Excavations at Tepe Yahya, Iran 1967-1975, the Third Millennium. Cambridge, MA: Peabody Museum of Archaeology and Ethnology, Harvard University, 2001.

Le Breton, L. "The Early Periods at Susa, Mesopotamian Relations." Iraq 19, no. 2 (1957): 79-124.

Madjidzadeh, Y. Jiroft: The Earliest Oriental Civilization. Tehran: Ministry of Culture and Islamic Guidance, Printing and Publishing Organization, Cultural Heritage Organization, 2003.
Madjidzadeh, Y., and H. Pittman. "Excavations at Konar Sandal in the Region of Jiroft in the Halil Basin: First Preliminary Report (2002-2008).” Iran 46 (2008): 69-103.

Masson, V. M. Altyn-Depe. Philadelphia: University Museum, University of Pennsylvania, 1988.

Mecquenem de, R. "Offrandes de fondation du temple de Chouchinak." Mémoires de la Délégation en Perse 7 (1905): 61-130.

Mecquenem de, R. "Fouilles de Suse 1929-1934." Mémoires de la Mission Archéologique de Perse 25 (1934): 177-237.

Mutin, B. "Cultural Dynamics in Southern Middle-Asia in the Fifth and Fourth Millennia BC: A Reconstruction Based on Ceramic Traditions." Paléorient 38, no. 1/2 (2012): 159184.

Mutin, B. The Proto-Elamite Settlement and Its Neighbors; Tepe Yahya Period IVC. Edited by C. C. LambergKarlovsky. American School of Prehistoric Research Monograph Series. Oxford and Oakville, CT: Harvard University and Oxbow Books, 2013.

Mutin, B. "Ceramic Traditions and Interactions on the SouthEastern Iranian Plateau During the Fourth Millennium BC." In Ancient Iran and Its Neighbours: Local Developments and Long-Range Interactions in the Fourth Millennium BC, edited by C. A. Petrie, 253-276. British Institute of Persian Studies Archaeological Monographs Series. Oxford: Oxbow Books, 2013.

Mutin, B., H. Moradi, H. Sarhaddi-Dadian, H. Fazeli Nashli, and M. Soltani. "New Discoveries in the Bampur Valley (South-Eastern Iran) and Their Implications for the Understanding of Settlement Pattern in the Indo-Iranian Borderlands During the Chalcolithic Period." Iran 55, no. 2 (2017): 99-119.

Mutin, B., L. D. Minc, C. C. Lamberg-Karlovsky, and M. Tosi. "Regional and Long-Distance Exchanges of an Emblematic 'Prestige' Ceramic in the Indo-Iranian Borderlands. Results of Neutron Activation Analysis." Paléorient 43, no. 1 (2017): 141-163.

Parviz, A., and P. Khadish. "The Elite Early Bronze Age Graves at Gilvaran Khoram Abad." Modares Archaeological Research 4, no. 8 (2013): 93-113.

Perrot, J., and Y. Madjidzadeh. "Jiroft, Fabuleuse Découverte en Iran (editors) Dossiers d'Archéologie $\mathrm{N}^{\circ} 287$.” Octobre 2003.

Perrot, J., and Y. Madjidzadeh. "L'Iconographie des Vases et Objects en Chlorite de Jiroft, Iran." Paléorient 31, no. 2 (2005): 123-157.

Perrot, J., and Y. Madjidzadeh. "A travers l'ornementation des vases et objets en chlorite de Jiroft." Paléorient 32, no. 1 (2006): 99-112.

Petrie, C. A. "'Culture', Innovation and Interaction Across Southern Iran from the Neolithic to the Bronze Age (c. 6500-3000 BC).” In Investigating Archaeological Cultures, edited by B.W. Roberts and M. V. Linden, 151-182. New York: Springer.

Petrie, C. "The Chalcolithic in Southern Iran." In The Oxford Handbook of Ancient Iran, edited by C. A. Petrie, 120-158. Oxford Handbooks in Classics and Ancient History. Oxford: Oxford University Press, 2013.

Pfälzner, P., and N. A. Soleimani. "The ICAR - University of Tübingen South-of-Jiroft Archaeological Survey (SOJAS). Results of the First Season 2015." Archäologische Mitteilungen aus Iran und Turan 47 (2017): 105-141. 
Pfälzner, P., N. A. Soleimani, and M. Karimi. "SOJAS 20152018: A Résumé of Four Seasons of Archaeological Survey South of Jiroft." Archaeology, Journal of the Iranian Center for Archaeological Research 2, no. 2 (2019): 107-124.

Piperno, M. "Micro-Drilling at Shahr-i Sokhta: the Making and Use of Lithic Drill-Heads." In South Asian Archaeology. Papers from the First International Conference of South Asian Archaeologists Held in the University of Cambridge, Vol. 1, edited by N. Hammond, 119-129. London: Duckworth, 1973.

Piperno, M., and S. Salvatori. The Shahr-i Sokhta Graveyard (Sistan, Iran). Excavation Campaigns 1972-1978. Rome: IsIAO, 2007.

Piran, S., and M. Hesari. Cultural Around Halil Roud and Jiroft. The Catalogue of Exhibition of Select Restituted Objects. Teheran: National Museum of Iran, 2005.

Piran, S., and Y. Madjidzadeh. Objects from the Jiroft Treasury, Soft Stone and Alabaster Objetcs (Recovered Collection) from the Halil River Basin. Tehran: National Museum of Iran, Pazineh Press,, 2013.

Pottier, M.-H. Matériel funéraire de la Bactriane méridionale de l'âge du Bronze. Paris: ERC, 1984.

Prickett, M. E. "Land and Water: Settlement Distribution and the Development of Irrigation Agriculture in the Upper Rud-i Gushk Drainage, South-Eastern Iran.” PhD diss., U.M.I. Dissertation Information Service. Cambridge, MA: Harvard University, 1986.

Rafifar, J., R. Micheli, and M. Vidale. "Janbe hayy as fannavary mathekhary dar Konar Sandal Junuby” (in Persian). In First International Conference of Archaeological Research in Jiroft: 2004. The Halil Rud Civilization, edited by Y. Madjidzadeh, 127-143. Tehran: Cultural Heritage, Handicrafts \&Tourism Organization of Kerman Province, 2008.

Sajjadi, S. M. S. "Prehistoric Settlements in the Bardsir Plain, South-Eastern Iran.” East and West 37, no. 1-4 (1987): 111-130.

Sajjadi, S. M. S. Excavations at Shahr-e Sukhteh, Graveyard 1997-2000 Preliminary Report. Tehran: Cultural and communication vice directorate, central office of cultural affairs, 2007.

Salvatori, S. "Gonur-Depe 1: The Middle Bronze Age Graveyard, Preliminary Report on the 1994 Excavation Campaign." Rivista di Archeologia 19 (1995): 5-37.

Salvatori, S. "Thinking Around Grave 3245 in the "Royal Graveyard' of Gonur (Murghab Delta, Turkmenistan).” In On the Track of Uncovering a Civilization. A Volume in Honour of the 80th-Anniversary of Victor Sarianidi, 244-257. Moscow: Russian Academy of Sciences, 2010.

Sarianidi, V. Necropolis of Gonur. Athens: Karon Editions, 2007.

Sarzec de, E. Découvertes en Chaldée. Paris: E. Leroux, 18841912.

Schmidt, E. F. Excavations at Tepe Hissar, Damghan. Philadelphia: University of Pennsylvania Press for the University Museum, 1937.

Shafiee, M., H. M. Salehi, and N. Eskandari. "Gahnegari nesbi va motlaq Tappeh Vakilabad Ourzouyeh ba estefade az ravesh tarikhgozari radiocarbon ba tif sanji jermi shetabdahande (AMS-14C): arziyabi gahnegari doreye Mes-o sangi Tappeh Yahya Soghan." [The Absolute and Relative
Chronology of Tepe Vakilabad: A Reappraisal of the Chronology of the Chalcolithic Period of Tepe Yahya in SE Iran.] Journal of Research on Archaeometry 5, no. 1 (2019): 81-94.

Soleimani, N. A. "First Season of Excavation in Tape Gavkoshi, Esfandagheh Plain/Jiroft." In A Collection of Archaeological Finds 2014-2015. 14th Annual Symposium on the Iranian Archaeology, 14-17. Tehran: Research Institute of Cultural Heritage and Tourism, 2016/1394.

Soleimani, N. A. "Tappeh Gāvkoshi Esfandagheh Jiroft, Esteghrāri az Doreh-ye Nosangi dar Jonub-e Shargh-e Irān.” [Tepe Gāvkoshi Esfandagheh, Jiroft; A Neolithic Occupation in Southeastern Iran.] In Proceedings of the 14th Annual Symposium of the Iranian Archaeology, March 6-8, 2016, Tehran, 385-389, 2016/1394.

Soleimani, N. A., M. Shafie, N. Eskandari, and H. M. Salehi. "Khaje Askar: A 4th Millennium BC Cemetery in Bam, Southeastern Iran.” Iranica Antiqua 51 (2016): 57-84.

Soleimani, N. A., and H. Fazeli Nashli. "Gahnegariye dorehye no-sangiye Kerman bar asas kavoshhaye bastanshenakhtiye Tappeh Gav Koshi, Esfandagheh-Jiroft." [The Reevaluation of Kerman Neolithic Chronology Based on the Excavation of Tepe Gav Koshi, Esfandagheh-Jiroft.] Journal of Research on Archaeometry 42, no. 2 (2019): 61-79.

Stein, A. Archaeological Reconnaissances in North-Western India and South-Eastern Iran. London: Macmillan, 1937.

Steinkeller, P. “Trade Routes and Commercial Networks in the Persian Gulf During the Third Millennium BC.” In Collection of Papers Presented to the Third International Biennial Conference of the Persian Gulf (History, Culture, and Civilization), edited by C. Faizee, 413-431. Tehran: Scientific Board of the Third International Conference of the Persian Gulf, Department of History, University of Tehran, 2013.

Steve, M. J., and H. Gasche. L'Acropole de Suse. Mémoires de la Délégation Archéologique en Iran 46. Paris: Geuthner, 1971.

Tallon, F. Métallurgie susienne I. Paris: Editions de la Réunion des Musées Nationaux, 1987.

Vidale, M. "Searching for Mythological Themes on the 'Jiroft' Chlorite Artefacts." Iranica Antiqua 50 (2015): 15-58.

Vidale, M., and F. Desset. "Mahtoutabad (Konar Sandal South, Jiroft), Preliminary Evidence of Occupation of a Halil Rud Site in the Early 4th Millennium BCE." In Ancient Iran and Its Neighbours: Local Developments and Long-Range Interactions in the 4th Millennium BC, edited by C. Petrie, 233-251. British Institute of Persian Studies, Archaeological Monographs Series. Oxford: Oxbow Books, 2013.

Vidale, M., M. Mariottini, G. Sidoti, and M. Zahir. "Early Evidence of Bead-Making at Mehrgarh, Pakistan: A Tribute to the Scientific Curiosity of Catherine and JeanFrançois Jarrige." In Stone Beads of South and Southeast Asia Archaeology, Ethnography and Global Connections, edited by A. K. Kanungo, 233-254. Gandhinagar: Indian Institute of Technology, 2017.

Vidale, M. Jiroft La civiltà che non c'era. Roma: ISMEO, 2020. Voigt, M. M., and R. H. Dyson, Jr. "The Chronology of Iran, ca. 8000-2000 B.C." In Chronologies in Old World Archaeology, edited by R. W. Ehrich, vol. 1, 122-178, vol. 2, 125-153. Chicago, IL: University of Chicago Press, 1992. 
Woolley, C. L. Ur Excavations, Vol. 2. The Royal Cemetery Text and Plates. London: Publications of The Joint Expedition of the British Museum and The Museum of the University of Pennsylvania to Mesopotamia, 1934.
Zarins, J. “Typological Study in Saudi Arabian Archaeology. Steatite Vessels in the Riyadh Museum." Atlal 2 (1978): 65-93.

Zettler, R. L., and L. Horne. Treasures from the Royal Tombs of Ur. Philadelphia: University of Pennsylvania Museum of Archaeology and Anthropology, 1998. 